\title{
EXTENSÃO NA UNIVERSIDADE FEDERAL DO PARANÁ: CONSTITUIÇÃO HISTÓRICA
}

\author{
Extension in the Federal University of Paraná: historical background
}

\author{
Nadia Gaiofatto Gonçalves ${ }^{1}$ \\ Carina Silva Vieira ${ }^{2}$ \\ Patrícia de Souza Antunes ${ }^{3}$
}

\begin{abstract}
RESUMO
Este artigo traz uma análise de concepções de Extensão que permearam e permeiam a história da Universidade Federal do Paraná. O trabalho foi elaborado com base em pesquisa bibliográfica, documentos históricos e depoimentos de pessoas que participaram do processo de institucionalização destas atividades na UFPR. Apresenta a relação entre a Universidade e demais segmentos da sociedade como uma permanência, embora com acepções distintas de acordo com cada contexto. Como principais resultados, destacam-se as mudanças construídas em âmbito nacional, em relação à Extensão Universitária, que foram apropriadas em normativas e na estrutura administrativa da UFPR; ao mesmo tempo em que são identificadas permanências de algumas acepções, e tensões decorrentes de diferentes concepções extensionistas que convivem na Universidade.
\end{abstract}

Palavras-chave: Universidade Federal do Paraná; Extensão Universitária; História.

\begin{abstract}
This article analyzes the concepts of Extension in the history of the Federal University of Paraná. The study was based on bibliographic research, historical documents and statements and reports by people who have taken part in the outreach institutionalization practices at the university itself. The article draws a comparison between the university and other segments of society as something permanent, albeit with different meanings that shift from one context to another. The changes constructed at the national level concerning university extension, which have been taken over by norms and by the administrative structure of the university stand out among the main findings of the study. At the same time, the study also found that some meanings have remained untouched while there has also been tension resulting from different concepts regarding extension at the university.
\end{abstract}

Keywords: Federal University of Paraná; University Extension; History.

\footnotetext{
1 Docente do Departamento de Teoria e Prática do Ensino e do Programa de Pós-Graduação em Educação da UFPR. E-mail: <nadiagg@ufpr.br>.

2 Graduada em Pedagogia pela UFPR. Mestre em Educação - PPGE/UFPR. Foi bolsista 100 Anos UFPR, e bolsista Reuni (no Mestrado). E-mail: carinavieira2@hotmail.com>.

3 Graduada em Pedagogia pela UFPR. Foi bolsista 100 Anos UFPR. E-mail: <pati.sou.antunes@gmail.com>.
}

GAIOFATTO, Nadia G; VIEIRA, Carina S. e ANTUNES, Patrícia S. Extensão na Universidade Federal do Paraná: trajetória histórica. Extensão em Foco, Curitiba: Editora da UFPR, nr.9, jan/jun 2014, p.3-49. ISSN 2358-7180. 
O presente artigo tem por objetivo apresentar um pouco da história da Extensão na Universidade Federal do Paraná (UFPR) ${ }^{4}$ visando a contribuir com o registro de sua constituição, pois ao compreender melhor o passado, também se pode melhor apreender o presente e suas configurações e desafios.

A pesquisa foi desenvolvida a partir de referenciais da História e da História da Educação, esta última compreendida como associada à primeira, pois tem como base o arcabouço teórico-metodológico desenvolvido na História, embora o aperfeiçoando e refinando em relação aos objetos específicos relativos à Educação (FONSECA, 2003) ${ }^{5}$. A História da Educação é assim, ao mesmo tempo, uma subárea da Educação e uma especialização da História. Para os historiadores da Educação isto tem significado uma forma de marcar o seu pertencimento à comunidade dos historiadores, e uma maneira de reafirmar a identificação de suas pesquisas com procedimentos próprios ao fazer historiográfico (FARIA FILHO; VIDAL, 2003, p. 60).

Para contemplar o objetivo desta pesquisa, o conceito de representação foi utilizado. A partir dele, Chartier (1988) aborda a questão das leituras, dos entendimentos possíveis, ou ainda das diferentes formas que uma realidade é dada a ler. Segundo ele, as percepções dos sujeitos sociais não são neutras dependendo do contexto em que foram elaboradas - derivando delas as suas práticas.

As representações construídas sobre o mundo não só se colocam no lugar deste mundo, como fazem com que os homens percebam a realidade e pautem a sua existência. São matrizes geradoras de condutas e práticas sociais, dotadas de força integradora e coesiva, bem como explicativa do real. Indivíduos e grupos dão sentido ao mundo por meio das representações que constroem sobre a realidade. (PESAVENTO, 2004, p. 39).

\footnotetext{
${ }^{4}$ Esta pesquisa foi desenvolvida no âmbito do Edital 100 Anos UFPR, sob a coordenação da professora Nadia G. Gonçalves, e contou com duas bolsas deste Edital, de agosto/2010 a abril/2012.

${ }^{5}$ Ressalta-se que essa compreensão se refere somente ao período mais recente, no Brasil. Faria Filho e Vidal (2003, p. 1) relacionam a constituição desse campo de conhecimento a três "pertencimentos: à tradição historiográfica do Instituto Histórico e Geográfico do Brasil (IHGB); às escolas de formação para o magistério e à produção acadêmica entre os anos 1940 e 1970".
}

GAIOFATTO, Nadia G; VIEIRA, Carina S. e ANTUNES, Patrícia S. Extensão na Universidade Federal do Paraná: trajetória histórica. Extensão em Foco, Curitiba: Editora da UFPR, nr.9, jan/jun 2014, p.3-49. ISSN 2358-7180. 
A visão de mundo constitui o mecanismo de justificativas individuais que permitem que o agente interaja com o mundo, por meio de suas práticas e representações - entendidas aqui como as diversas formas pelas quais a realidade pode ser interpretada, e que se refletem na vida prática, nas ações e atitudes, mesmo inconscientes. Estas representações dizem muito mais do que aquilo que enunciam, ou seja, trazem consigo sentidos ocultos, sutis, construídos social e historicamente, e que muitas vezes se internalizam no inconsciente coletivo, apresentando-se então como naturais, e, portanto, dispensando reflexão por parte daqueles que os compartilham, em dado espaço e momento histórico. Neste sentido,

[...] a força da representação se dá pela sua capacidade de mobilização e de produzir reconhecimento e legitimidade social. [...] As representações apresentam múltiplas configurações, e pode-se dizer que o mundo é construído de forma contraditória e variada, pelos diferentes grupos do social. Aquele que tem o poder simbólico de dizer e fazer crer sobre o mundo tem o controle da vida social e expressa a supremacia conquistada em uma relação histórica de forças. (PESAVENTO, 2004, p. 4).

Desta forma, compreende-se que estas representações permeiam tanto as normativas institucionais, quanto as práticas desenvolvidas pela comunidade acadêmica, relativas a atividades de Extensão na Universidade embora as práticas não sejam objeto deste trabalho.

Ao contemplar distintas fontes, pretendeu-se identificar percepções e representações acerca da Extensão na UFPR, considerando a necessidade de se compreender as questões históricas com um novo olhar sobre os documentos existentes, pois "a diversidade dos testemunhos históricos é quase infinita. Tudo que o homem diz ou escreve, tudo que fabrica, tudo que toca pode e deve informar sobre ele" (BLOCH, 2001, p. 79). Ainda sobre fontes históricas, Ragazzini propõe que elas sejam "lidas a partir de múltiplas relações, tais como as relações subjacentes à sua produção, seleção, modo de reunião, conservação e, também, de forma comparativa, na perspectiva de encontrar reiteração ou especificidade diferencial" (2001, p. 17). Essa foi a acepção assumida nessa pesquisa, para a compreensão e análise dos documentos escritos e das fontes orais.

GAIOFATTO, Nadia G; VIEIRA, Carina S. e ANTUNES, Patrícia S. Extensão na Universidade Federal do Paraná: trajetória histórica. Extensão em Foco, Curitiba: Editora da UFPR, nr.9, jan/jun 2014, p.3-49. ISSN 2358-7180. 
Segundo Bloch, "a ignorância do passado não se limita a prejudicar o conhecimento do presente: compromete, no presente, a própria ação" (2001, p. 40). Dessa forma o registro e a análise acerca da história e memórias sobre a Extensão na UFPR envolvem reconhecê-las nos diversos contextos sociais, econômicos, políticos e culturais, no Brasil, de forma mais ampla, com vistas a contribuir para o entendimento da atual concepção de Extensão presente na UFPR. Também envolvem caracterizar desafios, conquistas e dificuldades e, em especial, o processo de construção de sua legitimação como elemento intrínseco e necessário para a formação acadêmica promovida por esta Universidade.

Para averiguar a forma como institucionalmente a Extensão foi construída na trajetória histórica da UFPR, considerou-se as fontes escritas como essenciais para oferecer subsídios sobre as concepções e políticas de Extensão da UFPR. O olhar sobre essas fontes implica na identificação de documentos históricos institucionais da Universidade que contemplam a Extensão. As principais fontes encontradas e que foram utilizadas como referências neste trabalho são Leis e Decretos Federais; Estatutos e Regimentos da UFPR; Resoluções do Conselho de Ensino, Pesquisa (e Extensão); e atas do Comitê Acadêmico de Extensão (CAEX). Foram identificados nomes de pessoas que apareciam de forma recorrente nos registros sobre a Extensão e buscou-se localizar, contatar e convidar alguns deles para registrar seus depoimentos, seja por meio de entrevista, seja de forma escrita. Para tanto, foi utilizado como base um roteiro com questões consideradas relevantes para essa pesquisa.

Este artigo está organizado de modo a considerar três importantes momentos históricos na trajetória da Extensão no Brasil e na UFPR. Embora seja reconhecido que uma concepção não deixa de existir e outra nova é assumida homogeneamente a cada período, é possível identificar tendências, e estas foram utilizadas como referências para uma proposta de organização temporal do tema. Nestes momentos, observou-se a predominância de distintas concepções de Extensão. Em um primeiro momento ela é realizada por meio de cursos e conferências oferecidos à comunidade (difusão do conhecimento acadêmico), bem como prestações de serviço e atividades de 
divulgação artística e cultural. Nele, a Universidade levava o conhecimento e a técnica produzidos em seu âmbito, para fora dele, para os demais segmentos da sociedade.

O segundo momento representa a implementação, na UFPR, de um modelo que teve como base o Programa Nacional de Extensão, pautado na política de desenvolvimento e de segurança nacional do país, característica da ditadura civil-militar. No terceiro momento, a preocupação com a segurança e o desenvolvimento nacional foi gradativamente substituída primeiramente pela ideia da intelectualidade orgânica, e posteriormente pela concepção dialógica à luz de Paulo Freire; deslocando então o foco para a transformação social, firmando compromisso com a sociedade e com o processo de ensinoaprendizagem, e por fim, culminando em uma perspectiva mais recente de desenvolvimento social e sustentável.

Ao longo deste artigo serão abordados como, nesses contextos, estas concepções de Extensão Universitária foram apropriadas na UFPR, e representadas em suas normativas e documentos.

\section{Extensão como difusão de conhecimentos}

Este primeiro momento representa o início das atividades de Extensão na UFPR - então denominada Universidade do Paraná -, em que se buscava expressar ou entender o conhecimento e a técnica produzidos na Universidade para a sociedade, por meio de cursos e conferências oferecidos à comunidade, bem como algumas prestações de serviço. ${ }^{6}$

São características deste contexto as Universidades Livres ${ }^{7}$ no Brasil. As práticas extensionistas aparecem nessas instituições na forma de conferências, aulas públicas e cursos abertos à comunidade com temas como: "Fogo sagrado na Idade Média", "Grandes viagens e grandes viajantes"; "A Latinidade da Rumênia" e "A importância e Progresso da Otorrinolaringologia"8.

\footnotetext{
${ }^{6}$ De acordo com Justino (2001, p. 13) e Nogueira (2005) esta concepção decorre da Inglaterra (cursos, formação continuada) e dos Estados Unidos (prestação de serviços), e era comum no Brasil, no início do século XX.

7 Segundo apontamentos de Bacellar (1989) as Universidades Livres foram criadas no Brasil nos mesmos moldes das Universidades Populares europeias do século XVIII; organizadas sob forma de colégios e destinadas à educação das elites sociais da época.

${ }^{8}$ Conforme apontamentos de Bacellar (1989, p. 7) sobre a Universidade Livre de São Paulo.

GAIOFATTO, Nadia G; VIEIRA, Carina S. e ANTUNES, Patrícia S. Extensão na Universidade Federal do Paraná: trajetória histórica. Extensão em Foco, Curitiba: Editora da UFPR, nr.9, jan/jun 2014, p.3-49. ISSN 2358-7180.
} 
É possível perceber no Estatuto da Universidade do Paraná (UP), de 1913, uma preocupação com a comunidade externa, por meio do seu artigo 154, que se refere a práticas de ensino nas áreas de Medicina e Odontologia, denominadas como "aulas clínicas", realizadas sob forma de serviço:

As aulas de clínica serão diárias e dadas pela manhã, seja em enfermarias de hospital, seja em gabinetes ou dispensários para a pobreza mantidos pela Universidade. [...] nesses gabinetes todos os trabalhos serão gratuitos, fornecendo 0 cliente apenas o material quando se tratar de trabalho dispendioso. (UP, 1913 apud BACELLAR, 1989, p. 87).

Trata-se de uma prestação de serviço que se mantém dentro da formação como ensino e se desdobra no atendimento à comunidade.

O Estatuto da Universidade do Paraná de 1914, segundo Bacellar (1989), mantém a mesma linha do anterior, associando a prática, como exercício formativo, ao serviço comunitário, e ampliando a menção aos órgãos que deveriam prover esta oportunidade formativa aos estudantes:

Sob o nome de todos eles será mantido, pela Universidade um Hospital, uma Maternidade, a Policlínica Geral do Paraná, o Dispensário Dentário e a Farmácia, destinados a prestar assistência clínica gratuita à pobreza. Não a qualquer cliente, mas àquele, que queira prestar-se ao ensino dos alunos. (UP, 1914, apud BACELLAR, 1989, p. 90, grifos nossos).

Em 1931, sob o governo do Estado Novo de Getúlio Vargas, foi elaborado o Estatuto das Universidades Brasileiras ${ }^{9}$, com a primeira referência legal à Extensão Universitária no Brasil, que indica que a concepção extensionista na UP correspondia ao pensamento vigente à época, como pode ser observado em alguns artigos deste Decreto:

Art. 34 - a Extensão se fará através de cursos de Extensão destinados a divulgar, em benefício coletivo, as atividades técnicas e científicas dos institutos universitários; [...]

Art. 42 - a Extensão deverá se processar de cursos e conferências de caracter educacional ou utilitário uns e outros organizados pelos diversos institutos da universidade; [...] Art. 109 - Extensão é vista como difusão de conhecimentos filosóficos artísticos, literários e científicos e beneficio do aproveitamento individual. (BRASIL, 1931, grifos nossos).

\footnotetext{
${ }^{9}$ Decreto $19.851 / 31$ - conhecido como Reforma Francisco Campos.
}

GAIOFATTO, Nadia G; VIEIRA, Carina S. e ANTUNES, Patrícia S. Extensão na Universidade Federal do Paraná: trajetória histórica. Extensão em Foco, Curitiba: Editora da UFPR, nr.9, jan/jun 2014, p.3-49. ISSN 2358-7180. 
$\mathrm{Na}$ trajetória histórica da UP este Decreto tem desdobramento a partir do Estatuto de 1946, que não traz menção direta à Extensão, porém, no Regimento da UP do mesmo ano, há a ideia de intercâmbio como competência do novo Departamento Cultural, subordinado ao gabinete do Reitor:

Compete ao Assistente Técnico, Diretor do Departamento Cultural entre outras, as seguintes atribuições: organizar e dirigir os serviços do Departamento distribuídos pelas Divisões de Intercâmbio Cultural, Bibliotecas e Imprensa Universitária, que serão instaladas à medida das necessidades. (UP, 1946, apud BACELLAR, 1989, p. 92).

Com isso, as atividades extensionistas desse momento foram marcadas pelo intercâmbio universitário ${ }^{10}$, realizado por meio de conferências e seminários ministrados por professores visitantes, seja a convite do Reitor ou por estarem em trânsito pela capital do Estado do Paraná.

Este mesmo Regimento dispõe, em seu artigo 77, sobre os cursos oferecidos pela Universidade:

Art. 77 - Nos institutos universitários serão realizados os seguintes cursos: cursos normais, cursos equiparados, cursos de aperfeiçoamento, cursos de especialização, cursos livres, todos voltados para a clientela da Universidade. (UP, 1946, apud BACELLAR, 1989, p. 94, grifos nossos). ${ }^{11}$

A partir do Regimento de 1946 um Conselho Universitário da UP foi constituído. Uma de suas competências era organizar, de acordo com as propostas oriundas das Faculdades, os cursos, conferências e demais atividades de Extensão Universitária, como por exemplo, o Curso Intensivo sobre Tuberculose, realizado em 1946 pela Faculdade de Medicina, juntamente com a Sociedade Paranaense de Tisiologia (WESTPHALEN, 1987).

Um desafio para a UP, à época, foi conquistar sua federalização. Diversos esforços foram empreendidos durante os anos de 1940, o que foi conquistado por meio da Lei no 1.254, de 4 de dezembro de 1950 (BARANOW;

\footnotetext{
10 Bacellar (1989) relaciona intercâmbio com a Extensão quando aborda a ideia de abertura da Universidade para uma realidade nacional e internacional, saindo do âmbito apenas do atendimento à população carente.

11 Bacellar menciona ainda a existência da modalidade "Cursos de Extensão Universitária", mas sem maior detalhamento.
}

GAIOFATTO, Nadia G; VIEIRA, Carina S. e ANTUNES, Patrícia S. Extensão na Universidade Federal do Paraná: trajetória histórica. Extensão em Foco, Curitiba: Editora da UFPR, nr.9, jan/jun 2014, p.3-49. ISSN 2358-7180. 
SIQUEIRA, 2007, p. 115). Após esta federalização, foi organizado novo Estatuto da instituição, aprovado em 1952. Nele constam as nomenclaturas "cursos de graduação, pós-graduação e Extensão", bem como a organização das atividades de Extensão de forma explícita (POLICHUK, 1995).

Art. 28 - Parágrafo 3ํ: Os cursos de Extensão destinar-se-ão a difundir conhecimentos, técnicas e terão duas modalidades: Extensão popular e atualização cultural. (UFPR, 1952, apud BACELLAR, 1989, p. 95, grifos nossos).

As atividades de Extensão nesse período assinalam grande movimentação em sua dimensão cultural, a partir do Coral Universitário, criado em 1958, e da Orquestra Sinfônica da Universidade, fundada em 1946, que ganhou maior expressão em 1958, quando o então reitor, Flávio Suplicy de Lacerda, oficializou-a como entidade autônoma. De modo que, concretizavamse mais claramente as atividades do Departamento Cultural, previsto no Regimento de 1946, quando teve acrescidas, às suas atividades de serviço, as de divulgação artística e cultural.

No que tange à Extensão Universitária o Estatuto da UFPR de 1956 estabelece:

Art.17 - alínea "n": [...] Cabe ao Conselho Universitário resolver sobre assuntos atinentes de qualquer natureza, inclusive sobre o funcionamento e fiscalização de cursos equiparados de iniciativa da Universidade, bem como sobre medidas de mandatos e Extensão Universitária, ou destinados à melhoria do ensino e elevação do padrão cultural. [...]

Art. 30 - Os Regimentos das Unidades Universitárias definirão as modalidades dos cursos de graduação e de pós-graduação. As dos Cursos de Extensão deverão constar dos programas anuais e serão estabelecidos pelo Conselho Universitário mediante proposta do Reitor. [...]

Art. 34 - As condições de admissão aos cursos de Extensão serão definidas por instrução do Reitor em cada caso. (UFPR, 1956, apud BACELLAR, 1989, p. 96-97, grifos nossos).

A partir desse momento a Extensão é assumida na política da Universidade e expressa em seus planos anuais, contudo não há uma norma geral para o formato dos Cursos de Extensão, que eram adaptados às circunstâncias ou necessidades da UFPR, das equipes ou das comunidades envolvidas.

GAIOFATTO, Nadia G; VIEIRA, Carina S. e ANTUNES, Patrícia S. Extensão na Universidade Federal do Paraná: trajetória histórica. Extensão em Foco, Curitiba: Editora da UFPR, nr.9, jan/jun 2014, p.3-49. ISSN 2358-7180. 
Em 1961, a UFPR mantém seu formato de Extensão com o propósito de divulgar conhecimento e técnica. A Reitoria da Universidade, em consonância com o Conselho Universitário, propõe a oferta de cursos especiais, denominados "Cursos de Verão", com a finalidade de proporcionar ao povo paranaense a oportunidade de participar da vida universitária, (WESTPHALEN, 1987), e lança-se no país como pioneira no desenvolvimento da Universidade Volante ${ }^{12}$. Esta foi uma iniciativa que resultou de um convênio entre a Universidade, o governo do Estado do Paraná e a Escola Superior de Agricultura e Veterinária do Paraná. As atividades consistiam em uma série de cursos especiais, priorizando a interiorização da Universidade no Estado. Os cursos eram: eletivos/profissionais e de inscrição "livre e popular" (BACELLAR, 1989, p. 118).

No final de 1961, estabeleceu-se no Brasil a Lei de Diretrizes e Bases da Educação Nacional (№ 4024/61), que passou a reger o sistema educacional brasileiro. Esta, coloca os Cursos de Extensão no mesmo nível dos de Especialização e de Aperfeiçoamento, e estabelece que:

Art. 69 - Nos estabelecimentos de ensino superior podem ser ministrados os seguintes cursos: [...] c) especialização, aperfeiçoamento e Extensão, ou quaisquer outros, a juízo do respectivo instituto de ensino, abertos a candidatos com 0 preparo e os requisitos que vierem a ser exigidos. (BRASIL, 1961, grifos nossos).

Em contraposição à perspectiva da LDB, que parece tímida, "os estudantes universitários realizaram intensa atividade extensionista, mas desvinculada da instituição universitária", por meio da União Nacional de Estudantes, cuja diretriz era "a tentativa de aproximar a universidade e a sociedade, levando para o âmbito acadêmico a discussão dos problemas das classes populares" (NOGUEIRA, 2005, p. 20-21).

O Estatuto da UFPR, de 1962, está relacionado com a Lei acima mencionada e apresenta ajustes necessários a sua adequação, além de ressaltar o papel da Universidade, como, por exemplo, em seu artigo 3 .

\footnotetext{
12 Parte do Plano de Interiorização da UFPR com indicação na Programação Geral da Primeira Promoção da Universidade Volante - com data de 2 a 5 de agosto de 1961 como uma iniciativa ainda não experimentada em outras universidades.
}

GAIOFATTO, Nadia G; VIEIRA, Carina S. e ANTUNES, Patrícia S. Extensão na Universidade Federal do Paraná: trajetória histórica. Extensão em Foco, Curitiba: Editora da UFPR, nr.9, jan/jun 2014, p.3-49. ISSN 2358-7180. 
A formação universitária objetivará principalmente, as realidades brasileiras dos problemas regionais, como também se destinará aos superiores interesses da humanidade. (UFPR, 1962, apud BACELLAR, 1989, p. 99, grifos nossos).

Nota-se, neste primeiro momento, a representação de Extensão Universitária presente nos documentos de âmbito nacional e nos documentos internos à Universidade, que é marcada pela ideia de divulgação e difusão cultural (no sentido artístico) e de conhecimentos científicos, além de contemplar uma dimensão assistencial e de prestação de serviço. No período seguinte, será possível identificar elementos de permanências e também de mudanças quanto a essa concepção.

\section{Extensão e desenvolvimento}

Esse segundo momento tem início nos anos de 1960, com a ditadura civil-militar no Brasil.

Durante esse período, são identificadas três grandes ações de Extensão em âmbito federal, que compunham um Programa Nacional de Extensão Universitária: os Centros Rurais Universitários de Treinamento e Ação Comunitária (CRUTACs) (1966), o Projeto Rondon (1967) e o Campus Avançado (1969). Todos eles eram voltados para melhorias das condições de vida da população regional, associados à, e justificados, pela doutrina de segurança nacional e desenvolvimento, embora não ocorrendo uma ruptura com a concepção estabelecida nas décadas anteriores. Esta permanência pode ser observada, por exemplo, no Decreto-Lei 252/67, que estabelece em seu artigo 10:

A Universidade, em sua missão educativa, deverá estender à comunidade, sob forma de cursos e serviços, as atividades de ensino e pesquisa que lhe são inerentes.

Parágrafo único - Os cursos e serviços de Extensão universitária podem ter coordenação própria e devem ser desenvolvidos mediante a plena utilização dos recursos materiais e humanos da Universidade, na forma do que dispõe 0 art. $1^{\circ}$ do Decreto-Lei número 53 , de 18 de novembro de 1966. (BRASIL, 1967). 
Neste documento pode-se observar, mesmo que de forma muito embrionária, a relação da Extensão com o Ensino e a Pesquisa, embora com uma concepção distinta da assumida no início do século XXI. Nele, o Ensino e a Pesquisa constituem dimensões importantes da Universidade, sendo reconhecidos como atividades a ela "inerentes", considerando-se a necessidade de estendê-los à comunidade. Não estão presentes as ideias de inter-relação entre o Ensino, a Pesquisa e a Extensão, nem o diálogo com os demais setores da sociedade, predominando ainda a perspectiva unilateral por parte da Universidade. O texto do Decreto reitera a compreensão de que o conhecimento produzido na Universidade seria útil para a resolução de problemas regionais, como já indicava o Estatuto de 1962.

O Decreto de 1967 contribuiu para o desenvolvimento das ações de Extensão Universitária daquele período, que passaram a contar com apoio financeiro do governo federal, desde que vinculados ao seu Programa de Extensão Universitária. Logo depois ocorreu a Reforma Universitária (Lei oㅡ 5.540/68), que ratifica a presença da Extensão nas Universidades, como pode ser observado nos artigos que se seguem:

Art. $1^{\circ} \mathrm{O}$ ensino superior tem por objetivo a pesquisa, 0 desenvolvimento das ciências, letras e artes e a formação de profissionais de nível universitário.

Art. $2^{\circ} \mathrm{O}$ ensino superior, indissociável da pesquisa, será ministrado em universidades e, excepcionalmente, em estabelecimentos isolados, organizados como instituições de direito público ou privado. [...]

Art. 17. Nas universidades e nos estabelecimentos isolados de ensino superior poderão ser ministradas as seguintes modalidades de cursos.

d) de Extensão e outros, abertos a candidatos que satisfaçam os requisitos exigidos. [...]

Art. 32. Entendem-se como atividades de magistério superior, para efeitos desta lei:

a) as que, pertinentes ao sistema indissociável de ensino e pesquisa, se exerçam nas universidades e nos estabelecimentos isolados, em nível de graduação, ou mais elevado, para fins de transmissão e ampliação do saber; [...]

Art. 40. As instituições de ensino superior: a) por meio de suas atividades de Extensão, proporcionarão aos corpos discentes oportunidades de participação em programas de melhoria das condições de vida da comunidade e no processo geral do desenvolvimento. (BRASIL, 1968, grifos nossos). 
Observa-se claramente o destaque ao Ensino e à Pesquisa, e um papel dissociado destas dimensões formativas, atribuído à Extensão. Para Nogueira (2005, p. 26), nessa lei assume-se "a indissociabilidade entre atividades de ensino e pesquisa, tratando a Extensão como a forma através da qual a universidade estende à comunidade sua atividade de ensino e o resultado de suas pesquisas".

Por meio desta Lei, o Estado articulava mais fortemente as ações de Extensão realizadas nas Instituições de Ensino Superior aos interesses da nação, com a participação dos estudantes. Essa ênfase se expressa concretamente nas atividades extensionistas de modo que se soma ao CRUTAC e ao Projeto Rondon, o Programa Campus Avançado, coordenado pela Fundação Projeto Rondon, com o apoio do Ministério de Educação e Cultura (MEC) e do Ministério do Interior (MINTER). Este Programa tinha por objetivo que as Instituições de Ensino Superior assumissem, através de ações e serviços, os Campi Avançados em regiões distantes, oferecendo serviços e assistência à população regional (BACELLAR, 1989).

De acordo com Baranow e Siqueira (2007, p. 194), naquele contexto:

A Universidade deveria operar em termos da demanda socioeconômica e cultural da comunidade, visando a acompanhar e incrementar o processo social global. Por isso, os seus programas se definiam em razão da integração social. Estava integrada no CRUTAC e no Projeto Rondon. O primeiro tinha por objetivo a interiorização da UFPR na zona rural [...]. O Projeto Rondon atuava em regiões distantes, a exemplo do campus avançado de Imperatriz no Maranhão. A UFPR foi pioneira no sistema de interiorização das Universidades, onde atuou desde 1961, tendo realizado a ida das universidades volantes a várias regiões educacionais do Paraná, como ocorreu em Ponta Grossa, Londrina e Maringá. (grifos nossos).

O CRUTAC foi iniciado na UFPR em 1972/73, e tinha por objetivo proporcionar uma atuação dos estudantes da Universidade nas comunidades rurais do Paraná, em função de necessidades imediatas dessa população; e o Projeto Rondon, iniciado na UFPR em 1972, estava vinculado ao Ministério do Interior e Forças Armadas. Este último projeto objetivava a integração das regiões carentes ao plano de desenvolvimento do país, através do intercâmbio de estudantes de todas as regiões do Brasil. Para Nogueira (2005), tais ações

GAIOFATTO, Nadia G; VIEIRA, Carina S. e ANTUNES, Patrícia S. Extensão na Universidade Federal do Paraná: trajetória histórica. Extensão em Foco, Curitiba: Editora da UFPR, nr.9, jan/jun 2014, p.3-49. ISSN 2358-7180. 
são articuladas à doutrina de segurança nacional e desenvolvimento do governo, tanto por este considerar a educação como estratégica, quanto pela necessidade de evidenciar esforços no combate à miséria. Por vezes é destacada a dispersão, que tais ações promoviam, dos estudantes pelo país, o que seria de interesse dos governos militares por favorecer a desmobilização nas Universidades.

Nesse contexto, seguindo diretrizes da política educacional da época e as determinações para as atividades de Extensão, a UFPR, em seu Estatuto de 1970, apresenta os ajustes necessários:

Cap. I - Art. 2o - Alínea "c" - A Universidade, adotando métodos de funcionamento que preservem a unidade de suas funções de ensino e pesquisa, e assegurem a plena utilização de seus recursos humanos e materiais, destina-se: a) contribuir para a solução dos problemas de interesse da comunidade, sob a forma de cursos, estudos e serviços.

$[\ldots]$

Cap. V - Art. 7ㅇ: A Universidade proporcionará aos seus alunos: a) por meio de atividades de Extensão, oportunidade de participação em programas de melhoria das condições de vida da comunidade e no processo global de desenvolvimento; b) a realização de programas culturais, artísticos e desportivos; c) a Universidade proporcionara também a Educação Física, a Educação Moral e Cívica que se fará através de meios que propiciem aos seus alunos o conhecimento de seus deveres para com a sociedade e a pátria. (UFPR, 1970, apud BACELLAR, 1989, p. 103/104, grifos nossos).

Observa-se que a Extensão ainda não está presente como função da Universidade, de forma explícita, mas está, de certa forma, como uma de suas destinações (artigo $2^{\circ}$ ). No caso do artigo $7^{\circ}$, por outro lado, a Extensão encontra-se relacionada entre oportunidades a serem proporcionadas aos alunos, que se caracterizam em ações formativas, mais ou menos relacionadas à formação cívica condizente com as proposições dos governos militares daquele contexto.

Em 1972, tendo Algacyr Munhoz Mäder da Rocha como Reitor, a UFPR promove uma atividade de Extensão, com base na Universidade Volante, denominada "Mini-Campus": mediante convênios firmados com prefeituras municipais, as Faculdades de Agronomia e de Veterinária levaram, 
aos municípios de Coronel Vívida e de Foz do Iguaçu, equipes de professores e alunos que realizavam mensalmente, durante uma semana, palestras e demonstrações sobre assuntos agropecuários de interesse regional. Essa ação ampliou-se quando o então Reitor tomou conhecimento de um Programa do MEC, o CRUTAC, e estabeleceu uma parceria transformando o "Mini-Campus" em CRUTAC-PR, que foi implementado na UFPR a partir deste mesmo ano. $O$ programa tinha por objetivo proporcionar aos universitários da UFPR um treinamento em condições diferentes das vivenciadas na capital, prestando ação comunitária sob supervisão docente, como é possível observar no Regimento do CRUTAC-PR em seu artigo 1丷:

Art. 1ํ - O Centro Rural Universitário de Treinamento e Ação Comunitária do Paraná (CRUTAC-PR), criado pela Universidade Federal do Paraná, mediante a Portaria ํㅡ 8635, de 23 de maio de 1972, tem como objetivo fundamental: Proporcionar a universitários, supervisionados por seus mestres, treinamento em zona rural, prestando serviços às populações do interior com a finalidade de coadjuvar a resolução, parcial ou total, de problemas comunitários.

$\S 1$ 1 - O CRUTAC-PR não visa assumir a responsabilidade da solução de problemas de alçada de outros organismos municipais, estaduais ou federais, e sim integrar a Universidade na comunidade paranaense, proporcionando ao discente frutuoso contato com os problemas de cuja solução deverá participar como profissional. (UFPR. CRUTAC-PR, 1973, grifos nossos).

O início da atuação da UFPR no programa Campus Avançado também data de 1972, e ocorreu no Campus Avançado de Imperatriz, no Maranhão. As atividades realizadas envolviam cursos, palestras e orientações didáticas, pedagógicas e sociais, e contavam com equipes sob a responsabilidade do Grupo Tarefa Universitário (GTU) da UFPR. As equipes eram constituídas de professores e acadêmicos, nas mais diversas áreas: Agronomia, Arquitetura e Urbanismo, Biblioteconomia, Bioquímica, Comunicação Social, Ciências Biológicas, Direito, Economia e Administração, Educação, Educação Física, Engenharia Civil, Engenharia Florestal, Medicina e Enfermagem, e outras áreas ainda em colaboração com a Universidade Federal do Maranhão ${ }^{13}$

\footnotetext{
${ }^{13} \mathrm{Na}$ década de 1980, seguindo as orientações do Governo Federal, as Universidades deixaram de atender os "campus avançados" e em 21 de dezembro de 1985, pelo termo aditivo 42/83, a UFPR retirouse do Campus Avançado de Imperatriz - Maranhão, em caráter definitivo, deixando os trabalhos futuros

GAIOFATTO, Nadia G; VIEIRA, Carina S. e ANTUNES, Patrícia S. Extensão na Universidade Federal do Paraná: trajetória histórica. Extensão em Foco, Curitiba: Editora da UFPR, nr.9, jan/jun 2014, p.3-49. ISSN 2358-7180.
} 
(WESTPHALEN, 1987). Em âmbito nacional, a proposta do Programa Campi Avançados surge como resposta à crítica dos estudantes, quanto ao caráter esporádico das ações do Projeto Rondon, uma vez que o novo Programa tinha proposições mais contínuas e permanentes (NOGUEIRA, 2005).

Em seu depoimento, Marlene Walflor, servidora técnica desde 1990 atuando na Coordenadoria de Extensão/PROEC e na estruturação da Unidade de Programas e Projetos de Extensão, faz uma retomada desse processo histórico:

\begin{abstract}
Então, quando a Extensão começou a acontecer, foi em função da demanda dos alunos da universidade quererem espaço para eles irem a diferentes comunidades e/ou segmentos da sociedade levar os conhecimentos, fazer uma troca desses conhecimentos. Desse movimento surgiram algumas atividades de Extensão no sentido de levar assistência e o conhecimento, eram atividades mais assistenciais, levavam a informação do conhecimento sistematizado na formação de curso. Então é nesse momento que aparecem situações da construção do movimento da Extensão universitária. Em torno dos anos 60/70 essa movimentação dos alunos deu origem a duas ações que passaram a ser reconhecidas como ações extensionistas. Uma delas é a organização dos CRUTAC's, que eram centros rurais em que os alunos iam fazer trabalho de assistência (promoção do homem, desenvolvimento econômico social) junto com os produtores rurais (interior do Estado) e, outro é o Projeto Rondon, um movimento grande de intercâmbio de estudantes, os dois reconhecidos como atividades de Extensão. (WALFLOR, 2011).
\end{abstract}

Essas contribuições de Walflor reforçam e ilustram a trajetória da Extensão na UFPR, permitindo identificar a percepção de uma pessoa que vivenciou diretamente, seja administrativa, seja pedagogicamente, parte do processo de institucionalização da Extensão na Universidade. Pode-se destacar neste trecho do depoimento, a ênfase à participação e mobilização dos estudantes, que não é elemento presente nos documentos oficiais, até

sob a responsabilidade da Universidade Federal do Maranhão, ficando a UFPR apenas como colaboradora.

GAIOFATTO, Nadia G; VIEIRA, Carina S. e ANTUNES, Patrícia S. Extensão na Universidade Federal do Paraná: trajetória histórica. Extensão em Foco, Curitiba: Editora da UFPR, nr.9, jan/jun 2014, p.3-49. ISSN 2358-7180. 
mesmo pela característica destes, em que não são registradas as discussões para a construção das proposições, mas as normativas em sua versão final, e aprovadas pelas instâncias internas e externas à UFPR. Sobre a questão da origem dos CRUTACs e do Projeto Rondon, provavelmente ela se refere a iniciativas informais e demandas apresentadas, que posteriormente foram contempladas nestas ações do governo.

Ainda neste contexto, a Resolução 12/73 do então Conselho de Ensino e Pesquisa (CEP) ${ }^{14}$ da UFPR, órgão deliberativo da administração superior da Universidade, em seu Artigo 1º reforça a compatibilidade com a concepção de Extensão presente na política educacional nacional: "Entendem-se como cursos de Extensão, todos aqueles programados a serviço da comunidade ou que se destinarem a complementar o ensino e a pesquisa" (UFPR, CEP, 1973). Neste trecho, pode-se observar a ideia de articulação entre as três dimensões formativas, porém ainda com a Extensão como algo complementar, não necessariamente indispensável.

No sentido do estabelecido nesta Resolução, uma outra ação que poderia ser considerada extensionista, na fronteira com uma atividade de estágio, foi o Projeto Integração Universidade/Empresa/Governo, proposto a partir do Programa de Metas e Bases para Ação do Governo Federal em 1970, que associava a UFPR e o Intituto Euvaldo Lodi (IEL):

Este programa, instituído pelo convênio assinado em 1973, trazia o compromisso conjunto das duas instituições para realizar: treinamento profissional; visita a empresas e à universidade; encontros, estudos e debates em sistema de laboratórios; realização de pesquisas industriais e levantamento socioeconômico; e implantação de cursos de Extensão e complementação. (BARANOW; SIQUEIRA, 2007, p. 197)

Em 1973 também foi aprovado o plano de reestruturação da UFPR em decorrência da Reforma Universitária (Decreto no 72.782/1973). Posteriormente, em 1974, o novo Estatuto da UFPR ${ }^{15}$ segue a mesma

\footnotetext{
${ }^{14}$ A partir de 1997, o Conselho passa a utilizar a denominação CEPE (Conselho de Ensino, Pesquisa e Extensão) (Resolução 06/97 - CEPE).

${ }^{15}$ Portaria no 676, de 14 de novembro de 1974.
}

GAIOFATTO, Nadia G; VIEIRA, Carina S. e ANTUNES, Patrícia S. Extensão na Universidade Federal do Paraná: trajetória histórica. Extensão em Foco, Curitiba: Editora da UFPR, nr.9, jan/jun 2014, p.3-49. ISSN 2358-7180. 
abordagem do anterior, aperfeiçoando a correspondência entre a concepção de Extensão e a conjuntura nacional através da política educacional vigente:

Art. 55 - Por meio de atividades de Extensão a Universidade contribuirá para o desenvolvimento material e espiritual da comunidade.

Art. 56 - Os serviços de Extensão sob forma de serviços especiais, inclusive assessoria, atenderão a consultas e compreenderão estudos, a elaboração de projetos concernentes à matéria científica, técnica e educacional, bem como a participação em qualquer outra iniciativa de domínio científico, tecnológico, intelectual e artístico. (UFPR, 1974, apud BACELLAR, 1989, p. 106, grifos nossos).

Neste documento, pode-se destacar os tipos de desenvolvimento que a Universidade deveria fomentar: material e espiritual, condizentes com elementos centrais da doutrina de segurança nacional e desenvolvimento. Também, a expressão serviços de Extensão remete a uma permanência de práticas e de elementos de concepção, presentes nas primeiras décadas do século $X X$.

No Regimento Geral da Universidade, que operacionaliza o Estatuto de 1974, a Extensão Universitária ganha um pouco mais de espaço, mediante a criação da Pró-Reitoria de Assuntos Comunitários, encarregada da promoção e institucionalização do CRUTAC-PR, Projeto Rondon, Campus Avançado e de programas de integração Universidade-Empresa-Governo.

Cap. I - Art. 31, parágrafo $1^{\circ}$, item $3-$ a) os serviços de Assuntos Comunitários visarão promover a Extensão das atividades de ensino e pesquisa com o objetivo de contribuir para o progresso material da comunidade; b) relacionar a Universidade com a comunidade, promovendo atividades educacionais, culturais e artísticas; c) pesquisar e estudar os problemas paranaenses, a fim de que a universidade possa contribuir de modo decisivo para suas soluções; d) orientar e aconselhar o corpo discente em termos de assistência social e de saúde [...].

Cap. V - Art. 55 - Os cursos de Extensão serão oferecidos à comunidade com o propósito de divulgar conhecimento e técnicas de trabalho, podendo desenvolver-se em nível universitário ou não, de acordo com seu conteúdo e o sentido que assumam em cada caso. (UFPR, 1974, apud BACELLAR, 1989, p. 107/108, grifos nossos).

GAIOFATTO, Nadia G; VIEIRA, Carina S. e ANTUNES, Patrícia S. Extensão na Universidade Federal do Paraná: trajetória histórica. Extensão em Foco, Curitiba: Editora da UFPR, nr.9, jan/jun 2014, p.3-49. ISSN 2358-7180. 
Neste documento, ainda não é possível identificar a ideia de indissociabilidade, mas já começa a ser melhor elaborada a proposição de relação da Extensão com o Ensino e a Pesquisa, associada à função da Universidade perante a sociedade.

Em âmbito nacional, em 1974, ocorre a criação da CODAE Coordenação de Atividades de Extensão ${ }^{16}$, vinculada ao Departamento de Assuntos Universitários (DAU) do MEC, que, segundo Nogueira (2005), tinha uma concepção de Extensão derivada das proposições do Relatório Atcon ${ }^{17}$ que propunha "que a Extensão deveria ocupar lugar de destaque, devendo permear todos os níveis da instituição de Ensino Superior, através de múltiplas atividades culturais e científicas", e a universidade deveria ter suas funções de ensino, pesquisa e Extensão interligadas" (p. 31).

A partir de então a inter-relação que ocorreu, mediada pela CODAE, entre o CRUTAC e o Campus Avançado contribuiu para que a Extensão começasse a ser compreendida como uma terceira dimensão de ação da Universidade, ao lado do ensino e da pesquisa. Vale ressaltar o Plano de Trabalho da Extensão Universitária da CODAE em 1975, que teve por base a Reforma Universitária 5.540/68:

[...] a Extensão universitária é a forma através da qual a instituição de ensino superior estende sua área de atendimento às organizações, outras instituições e populações de um modo geral, delas recebendo um influxo no sentido de retro alimentação dos demais componentes, ou seja, o ensino e a pesquisa. (BRASIL, 1975, apud REIS, 1996, p. 03).

Segundo Rocha (2001), o Plano ${ }^{18}$ assume a Extensão como uma forma de diálogo entre a Universidade e os demais setores da sociedade, quando inclui as palavras "influxo' e "retro-alimentação" em seu texto. Neste documento, observa-se que a Extensão não está mais posta como algo

\footnotetext{
${ }^{16}$ Extinta em 1979.

17 Emitido pelo consultor norte-americano Rudolph Atcon, e que foi uma das bases para a elaboração da Reforma Universitária de 1968.

18 De acordo com Nogueira (2005, p. 36) ele trazia três linhas de ação: coordenação, supervisão e avaliação; articulação no nível das instituições, das experiências ali desenvolvidas; e a integração com órgãos públicos e privados.
}

GAIOFATTO, Nadia G; VIEIRA, Carina S. e ANTUNES, Patrícia S. Extensão na Universidade Federal do Paraná: trajetória histórica. Extensão em Foco, Curitiba: Editora da UFPR, nr.9, jan/jun 2014, p.3-49. ISSN 2358-7180. 
secundário ou complementar, mas no mesmo nível que as demais dimensões formativas do ensino superior, o Ensino e a Pesquisa.

Contudo, esta concepção ainda levaria algum tempo para começar a se fazer presente nas Universidades. A Extensão continuou sendo reiterada nos moldes tradicionais, como forma de divulgação dos saberes do mundo acadêmico sem troca de conhecimentos com a sociedade, como é possível perceber através das Resoluções 03/81 e 08/83 19 do CEP da UFPR.

Estas Resoluções apresentam uma concepção de Extensão focada em cursos, condizente com os Estatutos e Regimentos apresentados anteriormente, referente à divulgação de conhecimentos e técnicas de trabalho, conforme a citação abaixo, que descreve o artigo 1ำ de ambas as Resoluções:

Art. 1ํ Os cursos de Extensão são oferecidos pela Universidade à comunidade, com o propósito de divulgar conhecimento e técnicas de trabalho, como forma de estender-lhe o ensino de que se ocupa e que lhe é inerente. (UFPR, CEP, 1981; UFPR, CEP,1983).

O Estatuto da UFPR, de 1983, relaciona-se com o Estatuto de 1974, sem alterações significativas quanto à política universitária ou à Extensão propriamente dita. A principal mudança visível tanto no Estatuto quanto no Regimento é que a Extensão ganha um capítulo exclusivo, o que sugere que seu status começava a mudar na instituição. As finalidades da Extensão podem ser observadas no capítulo XIV, seção I do Regimento:

Art. 140 - A Extensão, como atividade humanística, deve proporcionar à comunidade, conhecimentos de arte, ciência e técnica, em caráter permanente e recíproco.

Art. 141 - São finalidades da Extensão:

I - colaborar por estudo, equacionamento e solução dos problemas das áreas menos desenvolvidas, contribuindo para a compensação de desequilíbrios regionais;

II - participar da tomada de consciência, formação e esclarecimento da opinião pública, no processo de desenvolvimento regional e nacional;

III - promover o levantamento do mercado de trabalho profissional qualificado na sua área de influência;

${ }^{19}$ Que dispõem sobre os cursos de Extensão na UFPR.

GAIOFATTO, Nadia G; VIEIRA, Carina S. e ANTUNES, Patrícia S. Extensão na Universidade Federal do Paraná: trajetória histórica. Extensão em Foco, Curitiba: Editora da UFPR, nr.9, jan/jun 2014, p.3-49. ISSN 2358-7180. 
IV - orientar alunos na integração de carreiras prioritárias para desenvolvimento regional e nacional;

$\mathrm{V}$ - assessorar científica, educacional e tecnicamente instituições e órgãos governamentais ou privados, de âmbito local, regional ou nacional e elaborar projetos por estes solicitados;

VI - manter intercâmbio com instituições econômicas de planejamento de pesquisa. (UFPR, 1983).

Conforme analisa Bacellar (1989, p. 109) não há alterações significativas entre os Estatutos e Regimentos de 1974 e 1983, apenas deslocamento na numeração dos artigos, portanto, sem alteração em seus conteúdos.

Em suma, neste contexto o que se percebe é que a UFPR participou das ações extensionistas voltadas para as Universidades públicas brasileiras, nos anos de 1960 e 1970 e início de 1980, por meio de atividades propostas pelo Programa Nacional de Extensão Universitária, consonante com a doutrina de segurança nacional e desenvolvimento. Porém, é preciso reconhecer que principalmente a partir da criação da CODAE, houve avanços quanto à institucionalização de Extensão (nas instituições e no MEC), o que, aos poucos, contribuiu para seu fortalecimento, como será apresentado a seguir.

\section{Extensão e transformação social}

Os anos de 1980 caracterizaram-se por lutas que reivindicavam a reestruturação dos âmbitos político, econômico, social e educacional, e a democratização do país.

Conforme os apontamentos de Silva (2008), no que tange à Extensão, a preocupação com a segurança e o desenvolvimento nacional foi substituída gradativamente pelo discurso do compromisso social, associado à concepção dialógica, à luz de Paulo Freire, concretizando o deslocamento do foco para a transformação social. Nesse momento a Extensão aponta para o compromisso com a sociedade e com o processo de ensino-aprendizagem em uma perspectiva transformadora.

Em 1985, a Pró-Reitoria de Assuntos Comunitários (PRAC) responsável, dentre outras competências, pela gestão da Extensão 
Universitária na UFPR, defende em seu relatório uma concepção de Extensão fundamentada em três critérios:

O primeiro critério é o de relevância social (a quem serve?). Deve haver uma clara opção por atividades e Extensão que privilegiem o compromisso político com as necessidades e os interesses da maioria da população. Entende-se que tal opção só se viabilizará se estiver integrada a uma política geral explicita para a Universidade. A partir daí impõe-se o segundo critério, que é o da integração da Extensão com as demais atividades da universidade. É inconcebível a Extensão como algo artificial e divorciado do saber produzido ou transmitido nos departamentos. A Extensão terá mais chance de se realizar a medida em que, a pesquisa e o ensino se vinculem, cada vez mais, às necessidades da comunidade em que a Universidade se insere. Por outro lado, a Extensão possibilita a realimentação contínua dos processos de ensino e pesquisa aproximando-os da realidade. O terceiro critério é o de se ter uma postura definida quanto às possibilidades e os limites da Extensão universitária no processo de transformação social. Isto supõe uma adequada compreensão da Universidade e do papel que ela pode desempenhar nesse processo. Com base nestes critérios, deve-se privilegiar a postura democrática na condução das ações extensionistas entre a comunidade universitária e a sociedade. (PRAC, 1985 apud BACELLAR, 1989, p. 150, grifos nossos).

A defesa da integração entre Ensino, Pesquisa e Extensão revela, por parte da PRAC, um novo olhar no que tange à concepção de Extensão, diferente do que vinha se desenvolvendo na UFPR ao longo dos anos anteriores. A presença dessa nova concepção também pode ser percebida nas reuniões do Comitê Assessor de Extensão (CAEX), que em suas atas no $10 \mathrm{e}$ no 12, de 1987, apresentava uma preocupação com a estrutura da PRAC; com a criação do Departamento de Apoio à Extensão; com a organização, comunicação e divulgação entre os Setores acerca dos trabalhos desenvolvidos na Extensão Universitária; com o Conceito de Extensão, sua institucionalização e as formas de financiamento dos Projetos.

Segundo Rodrigues (2004), o período compreendido entre março de 1985 e janeiro de 1990 foi reconhecido como "Nova República" e apresentou um governo mais acessível aos grupos sociais organizados. Neste período surgem muitas novas propostas governamentais, dentre elas, a Comissão Nacional para a Reformulação do Ensino Superior, o Programa Nova Universidade e o Grupo Executivo para a Reformulação do Ensino Superior.

GAIOFATTO, Nadia G; VIEIRA, Carina S. e ANTUNES, Patrícia S. Extensão na Universidade Federal do Paraná: trajetória histórica. Extensão em Foco, Curitiba: Editora da UFPR, nr.9, jan/jun 2014, p.3-49. ISSN 2358-7180. 
Em meio a essas ações, Rodrigues (2004) ressalta o movimento docente e dos dirigentes das instituições de Ensino Superior que participaram dessas discussões, procurando concretizar uma política que viesse a contemplar necessidades e interesses de segmentos mais amplos da sociedade brasileira, o que favorece e leva à criação do Fórum de Pró-Reitores de Extensão das Universidades Públicas Brasileiras (FORPROEX). O Fórum foi criado a partir do I Encontro de Pró-Reitores de Extensão das Universidades Públicas Brasileiras, em Brasília (1987) e destaca sua concepção de Extensão como:

\begin{abstract}
A Extensão Universitária é o processo educativo, cultural e científico que articula o ensino e a pesquisa de forma indissociável e viabiliza a relação transformadora entre a universidade e a sociedade. A Extensão é uma via de mãodupla, com trânsito assegurado à comunidade acadêmica, que encontrará, na sociedade, a oportunidade de elaboração da práxis de um conhecimento acadêmico. No retorno à Universidade, docentes e discentes trarão um aprendizado que, submetido à reflexão teórica, será acrescido àquele conhecimento. (FORPROEX,1987, apud BRASIL, 2000, grifo nosso).
\end{abstract}

A intenção era romper com a visão assistencialista e de prestação de serviço da Extensão, propondo que ela se efetivasse como uma relação interativa entre o saber acadêmico e o popular, a partir do confronto com a realidade, com a finalidade de possibilitar a produção de novos saberes e favorecer uma visão integrada e abrangente do social.

Somente na Constituição Federal de 1988 a Extensão foi legalmente equiparada ao Ensino e à Pesquisa. Para isso, contou com a defesa e o apoio de diversas instituições educacionais ${ }^{20}$, dentre elas o FORPROEX.

Art. 207 - As Universidades gozam de autonomia didáticocientífica, administrativa e de gestão financeira e patrimonial e obedecerão ao princípio de indissociabilidade entre ensino, pesquisa e Extensão. (BRASIL, 1988).

\footnotetext{
${ }^{20} \mathrm{Na}$ defesa da indissociabilidade entre ensino, pesquisa e Extensão, dentre as propostas encaminhadas à Constituinte podemos citar: "Plataforma educacional para a Constituição", da ANDES; "Proposta Educacional para a Constituição", do Fórum de Educação na Constituinte em Defesa do Ensino Público e Gratuito; "Proposta do Fórum de Pró-Reitores de Extensão das Universidades Brasileiras" e "Proposta da União dos Estudantes". (LIMA, 2009).
}

GAIOFATTO, Nadia G; VIEIRA, Carina S. e ANTUNES, Patrícia S. Extensão na Universidade Federal do Paraná: trajetória histórica. Extensão em Foco, Curitiba: Editora da UFPR, nr.9, jan/jun 2014, p.3-49. ISSN 2358-7180. 
Oficialmente é a primeira vez que a palavra indissociabilidade aparece e o texto legal sugere não haver hierarquia entre as três dimensões formativas nele abordadas. Merece destaque o sentido necessário da indissociabilidade, na Constituição: “obedecerão ao princípio", o que indica uma nova compreensão acerca do papel do ensino superior no Brasil, que se desdobra nas concepções de conhecimento e de formação do estudante, cidadão e profissional desejados.

No âmbito da UFPR, a Resolução 56/88 do CEP21 começa a apresentar algumas mudanças na definição de Extensão Universitária. A Extensão é compreendida não só como atividade de ensino (cursos), mas também poderia ser desenvolvida sob outra modalidade, conforme disposto nos artigos abaixo:

\begin{abstract}
Art. $2^{\circ}$ - São considerados programas de Extensão universitária, trabalhos envolvendo departamentos e demais órgãos da UFPR, estudantes e professores, em atividades vinculadas a questões básicas da sociedade brasileira em desenvolvimento com a comunidade.

Art. $3^{\circ}$ - São considerados cursos de Extensão universitária aqueles que, ofertados à comunidade objetivando a divulgação do conhecimento, busquem maior dinamização do processo de integração Universidade e Sociedade. [...]

Art. 9 - Os programas de Extensão universitária regidos pelas diretrizes contidas no preâmbulo desta resolução constituem instrumentos que visam à integração da Universidade com a Comunidade mediante trabalhos vinculados às atividades de ensino e pesquisa, possibilitando: a) praticas profissionais e acadêmicas que contribuam para a visão integrada do social; b) procedimentos que possam favorecer o desenvolvimento social, implicando na melhoria das condições de vida da população; c) fluxos que, estabelecendo a interação de saberes permitam viabilizar a relação transformadora entre a Universidade e a Sociedade. (UFPR, 1988, grifos nossos).
\end{abstract}

Mesmo no artigo 3ำ, sobre os Cursos de Extensão, embora retomando a expressão "divulgação do conhecimento", esta assume conotação distinta das anteriormente mencionadas, quanto ao objetivo desta divulgação. No artigo 9º o propósito da formação desejada aos estudantes está configurado, devendo favorecer uma "visão integrada do social", ao "desenvolvimento social" e à "interação de saberes".

\footnotetext{
${ }^{21}$ Dispõe sobre atividades de Extensão na Universidade Federal do Paraná.
}

GAIOFATTO, Nadia G; VIEIRA, Carina S. e ANTUNES, Patrícia S. Extensão na Universidade Federal do Paraná: trajetória histórica. Extensão em Foco, Curitiba: Editora da UFPR, nr.9, jan/jun 2014, p.3-49. ISSN 2358-7180. 
As propostas para a Extensão Universitária em âmbito nacional nos anos de 1980 convergem para a identificação da Extensão ao compromisso social, entendendo a integração Universidade-Comunidade como uma atividade plural e participativa. A mobilização das Universidades e a criação do Fórum de Pró-Reitores contribuem para conquistas importantes junto ao MEC, dentre elas destacando-se a criação da Divisão de Extensão e Graduação (DIEG), em 1990, e o Programa de Fomento à Extensão Universitária, criado em parceria com a Secretaria de Educação Superior (SESu/MEC), em 1993, que estabeleceu diretrizes para o financiamento destas atividades junto às Universidades.

No que se refere às normas de Extensão da UFPR, as atas do CAEX de número 28/90 e 29/91 apresentam a discussão e a aprovação da Bolsa Extensão, depois oficializada pela Resolução 16/91 do CEP, que institui e regulamenta o Programa Bolsa Extensão, com o seguinte propósito:

Art. $2^{\circ}$ - Viabilizar a participação de alunos, regularmente matriculados nos cursos de graduação e dos professores, no processo de interação entre Universidade e a Sociedade, por meio de trabalho sistemático que contribua para a formação acadêmica e profissional e o exercício da cidadania, consoante com sua área de formação. (UFPR, 1991).

Esta Resolução torna-se um marco importante a ser ressaltado na medida em que a Bolsa de Extensão é um grande incentivador e viabilizador do desenvolvimento de atividades extensionistas na UFPR. Neste mesmo ano, em artigo publicado pelas professoras Marcia Scholz de Andrade Kersten, na época Pró-Reitora de Extensão e Cultura ${ }^{22}$ (PROEC), e Eliana Barbosa Heemann no "Cadernos de Extensão 2" da UFPR, é possível perceber a concepção de Extensão assumida por essa gestão na Universidade:

Dentro desse contexto, a tradicional opção assistencialista da Extensão passa a ser entendida como o processo educativo cultural e científico que articula o ensino e a pesquisa de forma

\footnotetext{
22 Na reformulação das Pró-Reitorias a Pró-Reitoria de Órgão Suplementares (PROS) e a Pró-Reitoria de Assuntos Comunitários (PRAC) resultaram na PROEC, que se ocupa das atividades de Extensão e Cultura (POLICHUK, 1995, p. 71). Esta mudança foi formalizada pela Resolução COUN - 21/90, que promoveu a alteração do Estatuto da UFPR.
}

GAIOFATTO, Nadia G; VIEIRA, Carina S. e ANTUNES, Patrícia S. Extensão na Universidade Federal do Paraná: trajetória histórica. Extensão em Foco, Curitiba: Editora da UFPR, nr.9, jan/jun 2014, p.3-49. ISSN 2358-7180. 
indissociável e viabiliza a relação transformadora entre a Universidade e a Sociedade. A Extensão se constitui numa via de mão dupla em que a comunidade universitária encontrará na sociedade a oportunidade para a elevação da práxis de um conhecimento acadêmico. No retorno à Universidade, este conhecimento será objeto de discussão entre professores e alunos desencadeando a produção de um novo saber, resultante deste confronto entre saberes acadêmico e da população. Aqui, professores, alunos e população são atores, sujeitos no ato de aprender, que acontece em todos os espaços dentro e fora da Universidade e não apenas no espaço da sala de aula. Nessa perspectiva, a Extensão, além de instrumentalizadora do processo teoria/prática, se caracteriza como um trabalho intermultidisciplinar que favorece a visão da totalidade do social. (UFPR, PROEC, 1991).

Contudo, em contraposição a essa abordagem, o Estatuto da UFPR de 1992 apresenta uma concepção de Extensão semelhante às de 1970, 1974 e 1983:

Art. 55 - Por meio de atividades de Extensão a Universidade contribuirá para o desenvolvimento material e espiritual da comunidade.

Art.56 - Os serviços de Extensão, sob forma de serviços especiais, inclusive a assessoria, atenderão a consultas e compreenderão 0 estudo, a elaboração de projetos concernentes à matéria científica, técnica e educacional, bem como a participação em quaisquer outras iniciativas do domínio científico, tecnológico, intelectual e artístico. (UFPR, 1992, apud POLICHUK, 1995, p. 74).

Isso evidencia que havia concepções diferentes de Extensão se tensionando na UFPR. Nesse período, o CAEX, em 1992, começa a discutir e analisar uma proposta para a reformulação da Resolução № 56/88 do CEP, conforme indicação nas atas № 40,41,42,43 e 45/92, sendo que na nova proposta da Resolução 24/93 do CEP foi aprovado o entendimento da Extensão em uma concepção sócio-transformadora e de compromisso social:

Art. 1ํㅡ - Entende-se a Extensão Universitária como um processo educativo, cultural e científico que articula o Ensino e a Pesquisa de forma indissociável e que viabiliza a relação transformadora entre a Universidade e a Sociedade.

GAIOFATTO, Nadia G; VIEIRA, Carina S. e ANTUNES, Patrícia S. Extensão na Universidade Federal do Paraná: trajetória histórica. Extensão em Foco, Curitiba: Editora da UFPR, nr.9, jan/jun 2014, p.3-49. ISSN 2358-7180. 
Outro marco para a Extensão data de 1997, com a Resolução №06/97 do Conselho Universitário da Universidade, que aprova as alterações do Estatuto da UFPR, passando o artigo 15 do Estatuto constar da seguinte redação:

Art. 15 - A Administração Superior da Universidade será exercida pelos Conselhos de Planejamento e Administração (COPLAD), de Ensino, Pesquisa e Extensão (CEPE) e Universitário (COUN) como órgãos normativos, deliberativos e consultivos, e pela Reitoria como órgão executivo central. (UFPR, 1997, grifo nosso).

Essa mudança coloca a Extensão em nível de igualdade com o Ensino e a Pesquisa na administração superior. Isto é, o Conselho de Ensino e Pesquisa (CEP) passa a se chamar Conselho de Ensino, Pesquisa e Extensão (CEPE), e formaliza a institucionalização da Extensão na UFPR.

No âmbito nacional, em 1993, é criada a Comissão de Extensão Universitária, por meio da portaria n 66/SESu/MEC, cujo objetivo é "elaborar programas específicos que definam princípios, diretrizes e formas de fomento à Extensão nas IES" (NOGUEIRA, 2005, p. 50). Esta Comissão desenvolve uma proposta política para a Extensão Universitária, do qual faz parte o Programa de Fomento à Extensão Universitária, que tem, dentre suas diretrizes: a prioridade a ações "que rompam com a dependência econômica, cultural e política, como elemento essencial para a construção de cidadania" (p. 51); a indissociabilidade entre Ensino, Pesquisa e Extensão; que a "política de Extensão de cada universidade propicie a participação da comunidade universitária" (p. 52); o desenvolvimento da Extensão por meio de programas, projetos e eventos, através de ações sistematizadas; entre outros.

No cenário nacional, entretanto, a Lei de Diretrizes e Bases da Educação Nacional (Lei oㅡ 9394/96) não destaca tanto quanto seria desejável a Extensão, considerando-se o estabelecido na Constituição:

Art. $43^{\circ}$. A educação superior tem por finalidade:

I - estimular a criação cultural e o desenvolvimento do espírito científico e do pensamento reflexivo;

II - formar diplomados nas diferentes áreas de conhecimento, aptos para a inserção em setores profissionais e para a

GAIOFATTO, Nadia G; VIEIRA, Carina S. e ANTUNES, Patrícia S. Extensão na Universidade Federal do Paraná: trajetória histórica. Extensão em Foco, Curitiba: Editora da UFPR, nr.9, jan/jun 2014, p.3-49. ISSN 2358-7180. 
participação no desenvolvimento da sociedade brasileira, e colaborar na sua formação contínua;

III - incentivar o trabalho de pesquisa e investigação científica, visando o desenvolvimento da ciência e da tecnologia e da criação e difusão da cultura, e, desse modo, desenvolver 0 entendimento do homem e do meio em que vive;

IV - promover a divulgação de conhecimentos culturais, científicos e técnicos que constituem patrimônio da humanidade e comunicar o saber através do ensino, de publicações ou de outras formas de comunicação;

V - suscitar o desejo permanente de aperfeiçoamento cultural e profissional e possibilitar a correspondente concretização, integrando os conhecimentos que vão sendo adquiridos numa estrutura intelectual sistematizadora do conhecimento de cada geração;

VI - estimular o conhecimento dos problemas do mundo presente, em particular os nacionais e regionais, prestar serviços especializados à comunidade e estabelecer com esta uma relação de reciprocidade;

VII - promover a Extensão, aberta à participação da população, visando à difusão das conquistas e benefícios resultantes da criação cultural e da pesquisa científica e tecnológica geradas na instituição. (BRASIL, 1988)

Embora dimensões extensionistas possam ser identificadas em quase todos os tópicos deste artigo da Constituição, no inciso VII é possível identificar uma perspectiva que parece ir de encontro à nova concepção de Extensão que foi desenvolvida ao longo dos anos, pois enfatiza a difusão do conhecimento, e não estabelece explicitamente a necessidade de diálogo com outros saberes e segmentos da sociedade, embora no item VI mencione a reciprocidade. A LDB não define diretamente o que seja Extensão, pressupondo um entendimento comum desta atividade em âmbito nacional nas Instituições de Ensino Superior (IES), o que reflete um certo desconhecimento ou ignorância do contexto, no qual há tensões entre distintas concepções. Talvez a omissão no estabelecimento de uma concepção mais clara e atual de Extensão tenha sido estratégica no sentido de não enfrentamento das tensões existentes.

Já o Plano Nacional de Extensão Universitária, elaborado entre 1999 e 2001, propunha-se nortear as Universidades no desenvolvimento das atividades de Extensão, de acordo com eixos temáticos ${ }^{23}$ ali delimitados, e contribuir para o fortalecimento e a disseminação de uma nova concepção de

23 Os eixos temáticos são oito: Comunicação, Cultura, Direitos Humanos, Educação, Meio Ambiente, Saúde, Tecnologia e Trabalho.

GAIOFATTO, Nadia G; VIEIRA, Carina S. e ANTUNES, Patrícia S. Extensão na Universidade Federal do Paraná: trajetória histórica. Extensão em Foco, Curitiba: Editora da UFPR, nr.9, jan/jun 2014, p.3-49. ISSN 2358-7180. 
Extensão no país. A intenção era garantir o compromisso da Universidade com a transformação dos problemas sociais da sociedade sem tirar a autonomia das comunidades e sujeitos envolvidos, e com uma contribuição significativa para a mudança da sociedade. Os objetivos deste Plano são:

- Reafirmar a Extensão universitária como processo acadêmico definido e efetivado em função das exigências da realidade, indispensável na formação do aluno, na qualificação do professor e no intercâmbio com a sociedade;

- Assegurar a relação bidirecional entre a Universidade e a sociedade, de tal modo que os problemas sociais urgentes recebam atenção produtiva por parte da universidade;

- Dar prioridade às práticas voltadas para o atendimento de necessidades sociais emergentes como as relacionadas com as áreas de educação, saúde, habitação, produção de alimentos, geração de emprego e ampliação de renda;

- Estimular atividades cujo desenvolvimento implique relações multi, inter e/ou transdisciplinares e interprofissionais de setores da universidade e da sociedade. (BRASIL, 2000/2001, p. 8, grifo nosso).

$\mathrm{Na}$ política de Extensão expressa nesse Plano, consta a seguinte definição:

A Extensão Universitária é o processo educativo, cultural e científico que articula o Ensino e a Pesquisa de forma indissociável e viabiliza a relação transformadora entre a Universidade e a Sociedade. (FORPROEX, 2000/2001, p. 5).

Apresenta ainda a institucionalização da Extensão Universitária como essencial para a política de Extensão, incluindo conceito, diretrizes, finalidades ou funções bem definidas em instâncias de deliberação superior das Instituições Públicas de Ensino Superior (IPES).

A lei no 10.172/2001, que aprovou o Plano Nacional de Educação (PNE), demonstra um reconhecimento de um espaço para a Extensão, quando ressalta a sua necessidade no processo de formação promovido pelas Instituições Federais de Ensino Superior (IFES):

Meta 23 do item 4 do PNE: Implantar o Programa de Desenvolvimento da Extensão Universitária em todas as Instituições Federais de Ensino Superior no quadriênio 20012004 e assegurar que, no mínimo, 10\% de créditos exigidos para a graduação no ensino superior no País será reservado

GAIOFATTO, Nadia G; VIEIRA, Carina S. e ANTUNES, Patrícia S. Extensão na Universidade Federal do Paraná: trajetória histórica. Extensão em Foco, Curitiba: Editora da UFPR, nr.9, jan/jun 2014, p.3-49. ISSN 2358-7180. 
para a atuação dos alunos em ações extensionistas. (BRASIL, 2001, p. 38).

O Plano Nacional de Extensão é tema de discussão e análise do CAEX da UFPR, como pode ser observado nas atas № 126, 127 e 133/2000, nos quais também foram abordados: a Comissão Nacional de Avaliação da Extensão, os Comitês Setoriais de Extensão e um estudo e proposições para implementação do documento "Avaliação da Extensão Universitária, Aspectos Metodológicos".

Em resposta ao Plano Nacional de Extensão Universitária e ao Plano Nacional de Educação, a UFPR, por meio do CEPE dispõe, em sua Resolução no 23/01, sobre as Atividades de Extensão na Universidade, estabelecendo a mesma concepção presente nestes documentos de âmbito nacional:

Art.1ํ - A Extensão Universitária é o processo educativo, cultural e científico que, articulado de forma indissociável ao Ensino e à Pesquisa, viabiliza a relação transformadora entre a Universidade e a Sociedade. (UFPR, 2001).

Sobre a competência da Extensão, a Resolução faz referência detalhada à sua institucionalização na UFPR, conforme disposto no artigo $2^{\circ}$ :

Art. $2^{\circ}$ - As atividades de Extensão serão coordenadas pela Pró-Reitoria de Extensão e Cultura (PROEC) a quem, de acordo com o Regimento Geral da Universidade, cabe propor aos Conselhos Superiores normas e políticas sobre atividades de Extensão universitária, bem como fomentar, acompanhar, avaliar, articular e divulgar as atividades de Extensão no âmbito interno e externo da Universidade, contando com um Comitê Assessor de Extensão (CAEX) e Comitês Setoriais. (UFPR, 2001).

Ao longo da Resolução, as competências e atribuições são estabelecidas, bem como as normas para reger a Extensão: os programas, projetos, cursos, eventos, prestação de serviços, produção e publicação e recursos financeiros. A Resolução 23/01 (CEPE) constitui-se na base para 0 estabelecimento de critérios para a distribuição das Bolsas, em reunião da Comissão Bolsa Extensão, conforme atas do CAEX no 188/04, 201/05 e 215/06. Nos anos seguintes os critérios foram modificados algumas vezes, buscando-se o seu aperfeiçoamento, a exemplo do disposto na Ata 215/06:

GAIOFATTO, Nadia G; VIEIRA, Carina S. e ANTUNES, Patrícia S. Extensão na Universidade Federal do Paraná: trajetória histórica. Extensão em Foco, Curitiba: Editora da UFPR, nr.9, jan/jun 2014, p.3-49. ISSN 2358-7180. 
1- O Programa/projeto deverá estar em conformidade com a resolução citada. 2- Ter caráter multi e interdisciplinar e interprofissional, assegurando a participação de professores ou pesquisadores das áreas específicas e ter alunos envolvidos, possibilitar a participação de técnicos especializados da UFPR. 3 - articular ensino e pesquisa no seu desenvolvimento. 4 - proporção de bolsa ao número de professores envolvidos. 5 - projetos solicitando 1 e 2 bolsas foram contemplados na totalidade. 6 - ser apresentado em evento científico ou de Extensão universitária pelo menos 1 vez ao ano, principalmente no ENEC. (UFPR, CAEX, ata no 215,2006 , grifos nossos).

Estes ajustes são condizentes com a preocupação recorrente deste Comitê em ajustar a política de Extensão da UFPR a uma concepção de Extensão pautada na indissociabilidade com o Ensino e a Pesquisa, como pode ser observado em uma das atas de suas reuniões:

O Plano estratégico da gestão atual da PROEC é priorizar o caráter interdisciplinar da Extensão universitária trazendo-a para um nível de reconhecimento igual ao dado à pesquisa e ao ensino. O desafio da Pró-reitora é equilibrar as ações de Extensão e cultura. A Extensão está normatizada e a cultura ainda é uma área pouco institucionalizada. Outro compromisso é revisar a resolução da Extensão universitária, pois esta de um lado normatiza as atividades de Extensão e de outro dificulta 0 andamento dos procedimentos requeridos para aprovação e registro das mesmas. (UFPR, CAEX, ata no 149 , 2002, grifos nossos).

Esta preocupação não era somente interna à UFPR. Para atender as exigências do Plano Nacional de Extensão Universitária, o FORPROEX divulga em 2007 um documento chamado "Extensão Universitária: organização e sistematização" com o intuito de dar continuidade à primeira edição do livro "Sistema de Dados e Informações da Extensão/Base Operacional" e divulgar informações básicas que possam ser úteis a novos dirigentes e participantes da Extensão Universitária no Brasil. O documento define de forma didática e concisa as Diretrizes para a Extensão Universitária que devem estar presentes em todas as ações de Extensão e que podem ser expressas em quatro eixos: Impacto e transformação; Interação dialógica; Interdisciplinaridade e Indissociabilidade ensino-pesquisa-Extensão (FORPROEX, 2007, p. 17).

GAIOFATTO, Nadia G; VIEIRA, Carina S. e ANTUNES, Patrícia S. Extensão na Universidade Federal do Paraná: trajetória histórica. Extensão em Foco, Curitiba: Editora da UFPR, nr.9, jan/jun 2014, p.3-49. ISSN 2358-7180. 
O documento orienta a organização das atividades de Extensão universitária, sua articulação com a sociedade, e sua divulgação através da Rede Nacional de Extensão, RENEX ${ }^{24}$. Esta rede foi uma iniciativa do FORPROEX, que visava manter o cadastro das instituições, divulgar ações extensionistas universitárias e coordenar o Sistema Nacional de Informações de Extensão, SIEX/Brasil25, através de um aplicativo web, criado para divulgação das ações de Extensão universitária do país, com um banco de dados inter-relacional.

Para atender e adequar a Política de Extensão da UFPR a essas exigências, o CEPE aprova a Resolução № 70/08 que dispõe sobre as ações de Extensão na UFPR. Conforme a Resolução, essas ações deverão ser expressas em quatro eixos, conforme as diretrizes apresentadas no documento do FORPROEX sobre a Extensão Universitária, bem como serem submetidas à avaliação sistemática, de acordo com o Programa de Avaliação Institucional da Universidade.

Em 2010, o CAEX começa a discutir ajustes necessários a esta Resolução. A estratégia adotada foi de inicialmente realizar uma consulta aberta à comunidade universitária, por meio dos Comitês Setoriais de Extensão, o que ocorreu durante o primeiro semestre daquele ano. Ao longo do segundo semestre e do primeiro semestre do ano seguinte, o CAEX discutiu a nova Resolução, que, devido a uma greve de servidores da Universidade, foi à discussão do CEPE no segundo semestre, sendo então aprovada (Resolução 72/11-CEPE). Nela, buscou-se melhor explicitar as modalidades de atividades de Extensão, de acordo com as diretrizes do FORPROEX, e também as responsabilidades dos envolvidos nestas ações, bem como, simplificar trâmites, dentro do possível, na dimensão administrativa.

Enquanto era discutida a Resolução das atividades de Extensão, em função do estabelecido pelo Decreto Federal 7.416/2010, relativo a Bolsas Extensão, o CAEX discute e elabora a nova Resolução de Bolsas Extensão, aprovada pelo CEPE no mês de abril (Resolução 25/11 - CEPE).

\footnotetext{
24 Para maiores esclarecimentos verificar o site <www.renex.org.br>.

${ }^{25}$ Verificar o site <www.siexbrasil.renex.org.br>.
}

GAIOFATTO, Nadia G; VIEIRA, Carina S. e ANTUNES, Patrícia S. Extensão na Universidade Federal do Paraná: trajetória histórica. Extensão em Foco, Curitiba: Editora da UFPR, nr.9, jan/jun 2014, p.3-49. ISSN 2358-7180. 
Desta forma, ao final de 2011, a Extensão na UFPR contava com duas normativas em consonância com as diretrizes mais amplas, em âmbito nacional. No caso da Resolução 72/11, fica estabelecida a concepção assumida institucionalmente:

Art. 1ำ A Extensão Universitária é um processo educativo, cultural, científico ou tecnológico, que articula o ensino e a pesquisa de forma indissociável e viabiliza a relação transformadora entre a Universidade Federal do Paraná (UFPR) e os demais segmentos da sociedade.

§ 1ำ A Extensão Universitária deverá ser desenvolvida sob a forma de Programa, Projeto, Curso, Evento ou Prestação de Serviço Extensionista, visando:

I- integrar o ensino e a pesquisa com demandas sociais, buscando comprometimento da comunidade universitária em todos os níveis, estabelecendo mecanismos que interrelacionem o saber acadêmico ao saber dos demais segmentos da sociedade;

II- socializar o conhecimento acadêmico e promover a participação efetiva de setores da sociedade na vida da Universidade;

III- incentivar na prática acadêmica a contribuição para o desenvolvimento da consciência social e política, formando profissionais-cidadãos;

IV- participar criticamente de propostas que objetivem 0 desenvolvimento regional, econômico, social e cultural; e

$\mathrm{V}$ - contribuir para o aperfeiçoamento, a reformulação e a implementação de concepções e práticas curriculares da UFPR, bem como para a sistematização do conhecimento produzido.

§ 2ํำ Os princípios que norteiam a Extensão Universitária são:

I- Impacto e Transformação que visa o estabelecimento de relação entre a UFPR e os demais segmentos da sociedade para uma atuação transformadora, voltada prioritariamente à formação acadêmica e a necessidades sociais;

II- Interação Dialógica que visa o estabelecimento e desenvolvimento de relação entre a UFPR e os demais segmentos da sociedade por meio do diálogo e da troca de saberes;

III- Interdisciplinaridade que visa o estabelecimento de interrelação ou integração de conhecimentos, metodologias profissionais no atendimento a demandas formativas e sociais; e

IV- Indissociabilidade Ensino, Pesquisa e Extensão que consiste no vínculo da Extensão Universitária ao processo de formação de pessoas e de geração de conhecimento envolvendo necessariamente docentes e discentes da UFPR. (UFPR, 2012).

GAIOFATTO, Nadia G; VIEIRA, Carina S. e ANTUNES, Patrícia S. Extensão na Universidade Federal do Paraná: trajetória histórica. Extensão em Foco, Curitiba: Editora da UFPR, nr.9, jan/jun 2014, p.3-49. ISSN 2358-7180. 
Outras ações institucionais somaram-se a estas, em 2012, ano do centenário da UFPR, como por exemplo, a publicação do Guia Rápido Extensão, que visa a divulgar de forma mais ampla as orientações e possibilidades da Extensão na Universidade; a construção e implementação do Sistema Integrado de Gestão da Extensão Universitária (SIGEU), com os objetivos de melhor publicizar as atividades extensionistas da UFPR, de agilizar e facilitar os trâmites de propostas e relatórios destas ações - e que, em um futuro desdobramento, pode permitir que todos os trâmites administrativos sejam realizados exclusivamente online; o Edital de Fortalecimento e Divulgação da Extensão da UFPR, com um aporte de quatrocentos mil reais da própria Universidade, voltado para a produção de materiais de divulgação, pedagógicos, educativos, e publicações que sistematizem conhecimentos produzidos, derivados de atividades extensionistas; e a aprovação pelo CEPE, da criação do Programa Docente Sênior Extensão 26 , para integração de professores aposentados às atividades extensionistas da Universidade. Esta iniciativa, até onde conseguiu-se apurar, é inédita no país.

Apesar deste conjunto de iniciativas, que visam a promover internamente, por caminhos diversos, uma determinada concepção de Extensão Universitária na UFPR, reconhece-se que há permanências de concepções que formalmente já estão ultrapassadas, porém, ainda permeiam práticas e representações de servidores, docentes e técnicos, como por exemplo, a dimensão assistencial e de prestação de serviço. Tais atividades não deixam de ter um viés extensionista, na medida em que há uma relação com outros segmentos da sociedade e também contemplam demandas destes segmentos, porém nem sempre se faz presente nestas ações, a dimensão formativa dos estudantes da Universidade, que deve ser fortalecida.

A concepção mais atual, formal e institucionalmente assumida de Extensão muda o foco para a necessária ênfase formativa destas atividades, com pressupostos bastante claros, tanto sobre o papel da Extensão Universitária na atividade docente e na formação do cidadão-profissional que se deseja formar, quanto sobre como a relação com outros segmentos da

\footnotetext{
${ }^{26}$ Resolução 69/12 - CEPE.
}

GAIOFATTO, Nadia G; VIEIRA, Carina S. e ANTUNES, Patrícia S. Extensão na Universidade Federal do Paraná: trajetória histórica. Extensão em Foco, Curitiba: Editora da UFPR, nr.9, jan/jun 2014, p.3-49. ISSN 2358-7180. 
sociedade deve ser construída. Dessa forma, um dos grandes desafios para os próximos anos deverá ser o incremento na formação continuada dos servidores, em especial docentes da UFPR, quanto à Extensão, bem como, sobre a sua presença nos Projetos Político Pedagógicos dos Cursos de Graduação, muito mais elaborada do que a atual, que em geral somente prevê a possibilidade de, entre as atividades formativas, o estudante envolver-se com ações extensionistas.

Este último desafio estará fortemente articulado ao Plano Nacional de Educação 2011-2020, em cuja proposta, prevê:

Meta 12: Elevar a taxa bruta de matrícula na educação superior para $50 \%$ e a taxa líquida para $33 \%$ da população de 18 a 24 anos, assegurando a qualidade da oferta.

Estratégias: [...]

12.7) Assegurar, no mínimo, $10 \%$ do total de créditos curriculares exigidos para a graduação em programas e projetos de Extensão universitária. (PROJETO DE LEI..., 2011, grifos nossos).

A partir dessa demanda, todos os Setores e Campi da UFPR deverão incrementar o desenvolvimento de Programas e Projetos, que são as atividades extensionistas menos pontuais e mais fortemente articuladas aos princípios e propósitos da Extensão, tal como está indicado na Resolução 72/11-CEPE. Avançar nesta direção implicará necessariamente em uma política institucional articulada entre as três Pró-Reitorias fim da Universidade: Pró-Reitoria de Extensão e Cultura (PROEC), Pró-Reitoria de Graduação e Ensino Profissional (PROGRAD), e Pró-Reitoria de Pesquisa e Pós-Graduação (PRPPG), estendendo a outras ações a parceria positiva e já concreta que é realizada por meio da Semana Integrada de Ensino, Pesquisa e Extensão (SIEPE), que em 2012 teve sua quarta edição.

Dessa forma, as ideias abaixo citadas - presentes no documento do Plano de Desenvolvimento Institucional da UFPR 2012-2016, nas quais o Ensino, a Pesquisa e a Extensão estão bem articuladas - devem ser orientadoras destas futuras ações:

[...] revelam-se como prioritárias para a UFPR dos próximos três decênios, conforme Pinto (1996):

GAIOFATTO, Nadia G; VIEIRA, Carina S. e ANTUNES, Patrícia S. Extensão na Universidade Federal do Paraná: trajetória histórica. Extensão em Foco, Curitiba: Editora da UFPR, nr.9, jan/jun 2014, p.3-49. ISSN 2358-7180. 
- estabelecimento de um novo paradigma para as atividades de ensino aprendizagem, de forma indissociada da pesquisa e da extensão;

- a produção de uma nova lógica de organização curricular que expresse uma nova concepção de currículo enquanto conjunto das atividades nucleares indispensáveis ao processo de produção/transmissão/incorporação/disseminação do saber;

- a avaliação contínua dos processos curriculares entendidos como currículos em ação, como forma de garantir a consonância dos fins da IES com as exigências sociais e o avanço científico-tecnológico;

- a qualificação didático-pedagógica do docente aliada ao desenvolvimento de propostas inovadoras quanto aos métodos e técnicas que levem em conta as especificidades dos diversos níveis de ensino e de sua clientela, dos diferentes cursos e turnos de funcionamento;

- o resgate da unidade dos cursos através do fortalecimento de suas instâncias coordenadoras e norteadoras, visando superar o tratamento fragmentado do conhecimento;

- a articulação com os demais níveis de ensino com vistas ao fortalecimento das relações entre as diferentes áreas do conhecimento, sobretudo daquelas voltadas à formação de professores para a educação básica;

- a integração com as forças sociais em todas as suas instâncias objetivando a inserção do aluno na realidade concreta enquanto processo que alia teoria e prática;

- o aperfeiçoamento pedagógico do sistema de acesso e das condições de permanência do aluno na instituição, de modo a possibilitar a afetiva democratização do ensino. (UFPR, 2012, p. 21).

No caso da Coordenadoria de Extensão, ela é responsável pela orientação, coordenação, supervisão e certificação de atividades de Extensão Universitária realizadas na UFPR e, juntamente com o Comitê Assessor de Extensão, mobiliza-se para fortalecer e difundir a Extensão nas práticas formativas da Universidade. Esta Coordenadoria, até o final de 2012, era composta por: Secretaria da COEX; Secretaria do CAEX; Unidade de Programas e Projetos de Extensão; Unidade de Cursos de Extensão; Unidade de Bolsas Extensão; Revista Extensão em Foco.

Considerando a implementação do Sistema Integrado de Gestão da Extensão Universitária (SIGEU), e desafios identificados para os próximos anos, indicados anteriormente, no início de 2013 foi realizada uma reestruturação de duas das Unidades da Coordenadoria de Extensão, a Unidade de Programas e Projetos de Extensão (UPP), e a Unidade de Cursos

GAIOFATTO, Nadia G; VIEIRA, Carina S. e ANTUNES, Patrícia S. Extensão na Universidade Federal do Paraná: trajetória histórica. Extensão em Foco, Curitiba: Editora da UFPR, nr.9, jan/jun 2014, p.3-49. ISSN 2358-7180. 
de Extensão (UCE). Ocorreu a extinção da UPP e da UCE, e a criação da Unidade de Desenvolvimento da Extensão (UDE), e da Unidade de Registro e Certificação de Extensão (URC).

Esta reestruturação deveu-se em especial, porque, com a implementação do SIGEU, não se sustentava mais a existência de uma Unidade específica para os Cursos de Extensão, e outra para Programas e Projetos, pois tanto os registros, quanto a emissão de relatórios e de certificados, passarão a ser mais agilizados, sistematizados e organizados com - Sistema. Com a criação da URC e da UDE, não há mais divisão das Unidades por tipo de atividade de Extensão (Cursos e Programas e Projetos), mas sim por suas distintas responsabilidades: a URC com função mais administrativa, e a UDE, com função mais formativa e de orientação conceitual e teórico-metodológica. E ambas, em suas atribuições, atenderão às atividades de Extensão de forma ampla, ou seja, a URC com todos os registros, e a UDE, na orientação para todos os tipos de atividades de Extensão, visando em especial, a construção de práticas e propostas extensionistas mais condizentes com a concepção assumida pela Universidade.

Compreende-se que desta forma, os desafios para a Extensão, indicados anteriormente, serão enfrentados com melhores condições, pois será possível acessar com maior eficiência, confiabilidade e agilidade, informações que possam subsidiar diagnósticos, decisões e demandas que possam surgir, além de que, o SIGEU, mediante o gerenciamento da URC, será também instrumento para mais ampla publicização das atividades extensionistas para o CAEX, a administração central, a PROEC, a comunidade UFPR de forma geral, e a comunidade externa à Universidade. Por outro lado, com a UDE, a comunidade UFPR poderá contar com fonte confiável e orientações e assessoria para a elaboração e desenvolvimento de propostas de atividades extensionistas, o que poderá ocorrer tanto em atendimentos ao público, quanto por meio de visitas técnicas aos Campi, Setores e atividades extensionistas; promoção de cursos e eventos; diálogo, discussões e apoio a Coordenações e Colegiados de Curso de Graduação, em especial sobre reformulações curriculares e inserção da Extensão Universitária como dimensão formativa a ser necessariamente contemplada nas matrizes curriculares e como obrigatória 
para os estudantes de graduação da Universidade; apoio ao CAEX quanto a materiais, subsídios e discussões necessárias para a Política de Extensão da UFPR e também para questões operacionais relacionadas às atividades extensionistas; desenvolvimento de instrumentos de avaliação e acompanhamento das atividades, entre outras ações e materiais que poderão ser produzidos, com vistas ao atendimento amplo de suas atribuições.

Desta forma, a reestruturação de duas Unidades da COEX faz parte de um processo construído ao longo dos últimos anos, visando ao fortalecimento e ampliação da Extensão na UFPR. Além das Secretarias e da Revista Extensão em Foco, as três Unidades que passaram a compor a Coordenadoria têm as seguintes atribuições gerais:

- Unidade de Bolsas Extensão (UBE) - executar ações técnicas de registro e controle, relativas aos Programas de Bolsas gerenciados pela COEX; orientar usuários (estudantes, docentes, técnicos) quanto às diretrizes, normas, documentos e prazos, referentes às Bolsas gerenciadas pela Unidade; e apoiar a Coordenadoria nas atividades de apoio logístico e de estruturação física;

- Unidade de Desenvolvimento de Extensão (UDE) - desenvolver ações formativas e de orientação diversas, para esclarecimento da comunidade UFPR acerca da Extensão Universitária, de acordo com a Política de Extensão da Universidade; desenvolver e implementar/aplicar instrumentos de avaliação da Extensão na UFPR, em parceria com o CAEX;

- Unidade de Registro e Certificação (URC) - executar as ações de registro e controle das atividades extensionistas, por meio do gerenciamento do SIGEU; orientar os usuários do Sistema quanto à sua operacionalização e a aspectos administrativos de registro e certificação da Extensão na UFPR; emitir relatórios sobre a Extensão desenvolvida na Universidade; providenciar a certificação de atividades extensionistas, de acordo com as normativas da UFPR.

Em um âmbito mais amplo, o FORPROEX continua discutindo, propondo e defendendo demandas da Extensão junto a diversas instâncias, em especial o MEC. Por exemplo, a ampliação de recursos destinados para o edital anual do Ministério, o PROEXT - Programa de Extensão Universitária; a presença da Extensão como fator com peso na fórmula da matriz orçamentária da 
Associação Nacional dos Dirigentes de Instituições Federais de Ensino Superior (ANDIFES); campos específicos da Extensão na Plataforma Lattes do CNPq (o que foi conquistado em 2012) e bolsa produtividade Extensão do CNPq; entre outros.

Em 2012 o Fórum aprovou o documento intitulado "Política Nacional de Extensão Universitária", que visa a orientar as instituições de ensino superior na construção de suas políticas formativas. Além de acrescentar uma nova diretriz ou princípio para a Extensão Universitária, a saber, o impacto na formação dos estudantes, o documento traz quinze principais objetivos desta Política, sendo que se destacam os dois primeiros:

1. Reafirmar a Extensão Universitária como processo acadêmico definido e efetivado em função das exigências da realidade, além de indispensável na formação do estudante, na qualificação do professor e no intercâmbio com a sociedade;

2. conquistar o reconhecimento, por parte do Poder Público e da sociedade brasileira, da Extensão Universitária como dimensão relevante da atuação universitária, integrada a uma nova concepção de Universidade Pública e de seu projeto político-institucional. (FORPROEX, 2012, p. 5-6).

Tais objetivos evidenciam desafios que são comuns às Universidades brasileiras, e relacionam-se aos objetivos que vêm sendo almejados pela PROEC na construção, fortalecimento e consolidação da Extensão na UFPR.

Dessa forma, é possível perceber que houve importantes conquistas institucionais da Extensão neste último contexto, decorrentes e articuladas a uma concepção extensionista mais participativa, crítica e formativa. Os desafios elencados acima, internos e externos à UFPR, são decorrentes dessa nova configuração, que demanda práticas diferenciadas, e também, uma forma diferente de se compreender o papel da Universidade perante outros segmentos da sociedade, a produção e função do conhecimento acadêmico, a formação do aluno, e as práticas docentes, que são temas muito importantes, mas que excedem o propósito deste artigo.

\section{Considerações finais}

GAIOFATTO, Nadia G; VIEIRA, Carina S. e ANTUNES, Patrícia S. Extensão na Universidade Federal do Paraná: trajetória histórica. Extensão em Foco, Curitiba: Editora da UFPR, nr.9, jan/jun 2014, p.3-49. ISSN 2358-7180. 
Neste trabalho foi apresentado um recorte da história da Extensão Universitária em âmbito nacional, e particularmente no caso da Universidade Federal do Paraná, a partir de documentos históricos oficiais que ajudaram a institucionalizar e legitimar a Extensão.

As concepções e representações relativas à Extensão ao longo do tempo, nas demais Universidades públicas e na UFPR indicaram, em diferentes perspectivas, a necessidade fundamental de se estabelecer uma maior interação entre a Universidade e outros segmentos da sociedade. O que ocorreu, de acordo com as conjunturas políticas de cada período, e o que caracteriza o papel histórico da Extensão é justamente aproximar a Universidade da comunidade externa, de modo que a concepção presente em cada um dos três momentos relatados reflete os modelos de Universidade e a sociedade presentes. É por meio da Extensão, como uma dimensão formativa assumida pela Universidade ao longo dos anos, que se concretiza a tentativa de resposta às indagações sobre a função e a presença da Universidade na sociedade. A Extensão aparece então como um caminho para a Universidade concretizar de forma mais efetiva o seu compromisso social.

As atividades de Extensão, conforme apresentado neste trabalho, foram conquistando um espaço importante no meio acadêmico, que culminou com a determinação sobre a indissociabilidade entre ensino-pesquisa-Extensão na Constituição de 1988. Contudo, a Extensão apresenta-se como um conceito e uma ação em construção permanente, pois os distintos contextos e práticas indicam demandas e exigem avanços para novas definições e novos compromissos.

Este breve histórico aponta que há ainda um longo caminho a percorrer, no sentido de que atualmente pode-se assumir que a Extensão está institucionalizada. Porém, apesar de haver avanços importantes, ainda são desafios, tanto a sua integração com 0 Ensino e a Pesquisa, quanto a construção e consolidação da indissociabilidade nas práticas docentes e nos Projetos Político-Pedagógicos dos Cursos de Graduação. Tais desafios são variáveis conforme os Setores e Campi da UFPR, pois as representações e a relação com a Extensão não são homogêneas internamente à Universidade, com significativas distinções, relacionadas às diversas áreas de conhecimento. 
Em favor desta desejável consolidação e do fortalecimento contínuo da Extensão, como elemento formativo essencial na nossa Universidade, está a certeza de que o docente que compreende a atual concepção de Extensão presente em normativas internas da UFPR e legitimadas nacionalmente - e o princípio da indissociabilidade, e começa a desenvolvê-los em suas atividades, assume-os como um princípio metodológico em sua prática, permitindo e contribuindo para que as comunidades interna e externa à Universidade, aos poucos, também se apropriem desta proposição.

A fim de contribuir para uma visualização mais direta da trajetória histórica e institucional da Extensão na UFPR, foi elaborado um anexo a este artigo, uma linha do tempo correspondente à sistematização mais objetiva dos dados aqui apresentados. Ressalva-se que a distribuição dos anos ao longo desta linha do tempo teve como prioridade o registro das iniciativas relativas à Extensão e a decorrente quantidade de informações consideradas relevantes em cada contexto.

É importante destacar que no recorte e no objetivo propostos para este artigo não foi abordada uma outra dimensão, fundamental para a compreensão das práticas e apropriações feitas pela comunidade da UFPR, acerca da Extensão Universitária: as ações, experiências e vivências de docentes, técnicos, estudantes e outros participantes, externos, de Programas e Projetos de Extensão. Isso, porque esta questão demandaria uma outra pesquisa, tão relevante quanto esta que foi aqui apresentada, e que fica como sugestão, como um trabalho a ser ainda realizado.

\section{REFERÊNCIAS}

BACELLAR, Yeda M. S. Extensão universitária: que vocação? Dissertação (Mestrado em Educação) - Universidade Federal do Paraná, Curitiba-PR, 1989. Mimeo.

BARANOW, Ulf G.; SIQUEIRA, Márcia D. (Orgs.). Universidade Federal do Paraná: história e estórias (1912-2007). Curitiba: Editora UFPR, 2007.

BLOCH, Marc. Apologia da história ou o ofício do historiador. Rio de Janeiro: J. Zahar, 2001.

BURMESTER, Ana M. O. (Org.). Universidade Federal do Paraná: 90 anos em construção. Curitiba: Editora UFPR, 2002. 
CAMPOS, Névio. Intelectuais paranaenses e as concepções de Universidade: 1892-1950. Curitiba: Editora UFPR, 2008.

CHARTIER, Roger. A história cultural. Entre práticas e representações. Lisboa: Difel, 1988.

FARIA FILHO, L. M.; VIDAL, D. G. História da educação no Brasil: a constituição histórica do campo (1880-1970). Revista Brasileira de História, São Paulo, v. 23, n. 45, p. 37-70, 2003.

FÁVERO, Maria L. A. A universidade no Brasil: das origens à Reforma Universitária de 1968. Educar em Revista, Curitiba, n. 28, jul./dez. 2006.

FICO, Carlos. Versões e controvérsias sobre 1964 e a ditadura militar. Revista Brasileira de História, 2004, v. 24, n. 47, p. 29-60.

FONSECA, Thaís N. L. História da educação e história cultural. In: VEIGA, C. G.; FONSECA, T. N. L. (Org.). História e historiografia da educação no Brasil. Belo Horizonte: Autêntica, 2003. p. 49-76.

GLASER, Niroá Z. R. R. Meio século de Educação na UFPR: uma crônica desde a Faculdade de Filosofia, Ciências e Letras e Instituto de Educação anexo ao Setor de Educação. Curitiba: Fundação UFPR, 1988.

GONÇALVES, Nadia G.; GONÇALVES, Sandro A. Desenvolvimentismo e Educação no Paraná (anos de 1960 e 1970). Diálogos, DHI/PPH/UEM, v. 12, n. 2/ n. 3, p. 143-171, 2008.

IPARDES - Fundação Édison Vieira. O Paraná reinventado: política e governo. Curitiba: Ipardes, 1989. (Coleção História Política do Paraná, 1ํ documento).

JUSTINO, Maria José. Extensão na ordem do dia. In: Guia de Extensão (atualização). Curitiba - UFPR, 2001, p. 13-22.

LEÃO, Igor Z. C. C. O Paraná nos anos 70. Curitiba: Ipardes/Concitec, 1989. (Ipardes, Coleção Teses, 1).

LIMA, Bárbara Souza. A Extensão Universitária no Curso de Educação Física da Universidade Federal do Maranhão: uma análise do projeto Jovens com a Bola Toda. 137 p. Dissertação (Mestrado em Educação) - Centro de Ciências Sociais, Universidade Federal do Maranhão, São Luís, 2009. Mimeo. Disponível em <http://biblioteca.universia.net/html_bura/ficha/params/id/ 49240718.html >. Acesso em: 09/11/2010.

MACUCO, Mara L. G.; ARCO-VERDE, Yvelise F. S. Histórico da Extensão na UFPR. In: PROEC-UFPR. Guia da Extensão na UFPR. Curitiba, 1998.

MAGALHÃES, Marion B. Paraná: política e governo. Curitiba: SEED, 2001. (Coleção História do Paraná: textos introdutórios).

MICHELOTTO, Regina M. A liberação do acesso e a Extensão como estratégias de democratização da Universidade: a experiência da Itália e do Brasil. Tese (Doutorado em Educação) - Universidade Federal de São Carlos, São Carlos - SP, 1999. Mimeo.

NOGUEIRA, Maria das Dores Pimentel. Políticas de Extensão Universitária Brasileira. Belo Horizonte: Editora UFMG, 2005. 
PESAVENTO, Sandra J. História e história cultural. 2. ed. Belo Horizonte: Autêntica, 2004.

POLICHUK, Meri de Oliveira. A Extensão universitária na Universidade Federal do Paraná. 110 p. Dissertação (Mestrado em Educação) - Pontifícia Universidade Católica do Paraná, Curitiba, 1995. Mimeo.

RAGAZZINI, Dario. Para quem e o que testemunham as fontes da História da Educação? Educar em Revista, Curitiba: UFPR, n. 18, p. 13-28, 2001.

REIS, Renato Hilário dos. Histórico, Tipologias E Proposições Sobre A Extensão Universitária no Brasil. Linhas Críticas. Revista Semestral da Faculdade de Educação - UNB, v. 2, n. 2, p. 41-47, abr./jul. 1996. Disponível

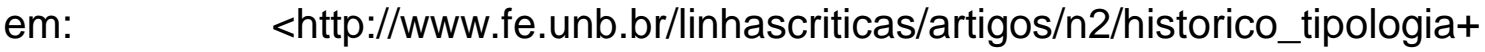
renato_hilario.pdf>. Acesso em: 08/11/2010.

ROCHA, R. M. Gurgel. A Construção do Conceito de Extensão universitária na America Latina. In: FARIA, Doris Santos de (Org.). Construção Conceitual da Extensão na America Latina. Brasília: Editora UNB, 2001.

RODRIGUES, Marilúcia de Menezes. A Extensão Universitária no Contexto da Nova República: as Propostas Oficiais dos Anos Oitenta. In: Artigos Originais em Extensão, Uberlândia, n. 4, v. 1, set. 2004.

ROUSSO, Henry. A memória não é mais a mesma. In: FERREIRA, M. M.; AMADO, J. (Orgs.). Usos e abusos da história oral. 5. ed. Rio de Janeiro: Ed. FGV, 2002. p. 92-114.

SAVIANI, Dermeval. Política e educação no Brasil - o papel do Congresso Nacional na legislação de ensino. São Paulo: Cortez, 1987.

SILVA, Francisco Carlos Lopes da. Universidade e Extensão: a trajetória em um Centro Universitário. Florianópolis. Tese (Doutorado em Engenharia da Produção) - Universidade Federal de Santa Catarina. Florianópolis, 2008.

TRINDADE, Etelvina M. C.; ANDREAZZA, Maria L. Cultura e educação no Paraná. Curitiba: SEED, 2001. Coleção História do Paraná: textos introdutórios.

WACHOWICZ, Ruy C. Universidade do Mate: história da UFPR. 2. ed. Curitiba: Editora UFPR, 2006.

WALFLOR, Marlene M. Entrevista concedida a Patrícia de Souza Antunes. 2011.

WESTPHALEN, Cecília Maria. Universidade Federal do Paraná: 75 anos. Curitiba: SBPH-PR, 1987.

Faculdade de Filosofia, Ciências e Letras do Paraná: 50 anos. Curitiba: SBPH-PR, 1988.

\section{DOCUMENTOS CONSULTADOS}

BRASIL, Lei no 10.172/2001, de 9 de janeiro de 2001. Aprova o Plano Nacional de Educação e dá outras providências. Diário Oficial da União, Brasília, DF, 10 jan. $2001 . \quad$ Disponível em: <http://www.planalto.gov.br/ccivil_03/leis/leis_2001/110172.htm>. Acesso em: 15/07/2011.

GAIOFATTO, Nadia G; VIEIRA, Carina S. e ANTUNES, Patrícia S. Extensão na Universidade Federal do Paraná: trajetória histórica. Extensão em Foco, Curitiba: Editora da UFPR, nr.9, jan/jun 2014, p.3-49. ISSN 2358-7180. 
. Lei no 9.394, de 20 de dezembro de 1996. Estabelece as Diretrizes e Bases da Educação Nacional. Disponível em: $<$ http://portal.mec.gov.br/seesp/arquivos/pdf/lei9394_ldbn1.pdf>. Acesso em: 15/07/2011.

. Constituição da República Federativa do Brasil de 1988. Brasília, 5 de outubro de $1988 . \quad$ Disponível em: <http://www.planalto.gov.br/ccivil_03/Constituicao/Constituicao.htm>. Acesso em: 18/07/2011.

Lei $n^{0}$ 5.540, de 28 de novembro de 1968. Fixa normas de organização e funcionamento do ensino superior e sua articulação com a escola média, e dá outras providências. Diário Oficial da União, Brasília, DF, 29 nov. 1968. Disponível em: <http://www.planalto.gov.br/ccivil_03/leis/ L5540.htm>.

. Senado Federal. Secretaria de Informação Legislativa. Decreto-Lei no 252, de 28 de fevereiro de 1967. Estabelece normas complementares ao Decreto-Lei no 53, de 18 de novembro de 1966, e dá outras providências. Diário Oficial da União, Brasília, DF, 28 fev. 1967. Disponível em: $<$ http://www6.senado.gov.br/legislacao/ListaPublicacoes.action?id=117229>. Acesso em: 12/03/2012.

. Presidência da República. Congresso Nacional. Lei oㅜ 4.024, de 20 de dezembro de 1961. Fixa as Diretrizes e Bases da Educação Nacional. Diário Oficial da União, Brasília, DF, 27 dez. 1961, retificado em 28 dez. 1961. Disponível em: <http://www.jusbrasil.com.br/legislacao/ 108164/lei-dediretrizes-e-base-de-1961-lei-4024-61 >. Acesso em: 16/03/2012.

. Senado Federal. Subsecretaria de Informações. Decreto oㅜ 19.851, de 11 de abril de 1931. Dispõe que o ensino superior no Brasil obedecerá, de preferência, ao sistema universitário, podendo ainda ser ministrado em institutos isolados, e que a organização técnica e administrativa das universidades é instituída no presente decreto, regendo-se os institutos isolados pelos respectivos regulamentos, observados os dispositivos do seguinte Estatuto das Universidades Brasileiras. Diário Oficial da União, Brasília, DF, 15 abr. 1931. Disponível em: $<$ www.fis.ufba.br/dfes/PDI/financ/decreto\%2019.851.doc>. Acesso em: 16/03/2012.

Plano Nacional de Extensão Universitária - Edição Atualizada. Brasil 2000/2001 Fórum de Pró-Reitores de Extensão das Universidades Públicas Brasileiras e SESU/MEC.

FORPROEX - Fórum de Pró-Reitores de Extensão das Universidades Públicas Brasileiras. Extensão Universitária: organização e sistematização. Coordenação Nacional do FORPROEX. Belo Horizonte: Coopmed, 2007.

Disponível

Política Nacional de Extensão Universitária. Manaus - AM, 2012.

<http://www.proec.ufpr.br/downloads/extensao/2012/legislacao/Politica\%20Naci onal\%20de\%20Extensao\%20Universitaria\%20maio2012.pdf>. Acesso em: 08/12/2012.

GAIOFATTO, Nadia G; VIEIRA, Carina S. e ANTUNES, Patrícia S. Extensão na Universidade Federal do Paraná: trajetória histórica. Extensão em Foco, Curitiba: Editora da UFPR, nr.9, jan/jun 2014, p.3-49. ISSN 2358-7180. 
KERSTEN, Marcia Scholz de Andrade; HEEMANN, Eliana Barbosa. Cadernos de Extensão 2. PROEC/UFPR, 1991.

PROJETO DE LEI - Plano Nacional de Educação 2011-2020. Congresso Nacional, $2011 . \quad$ Disponível em: $<$ http://portal.mec.gov.br/index.php?option=com_content\&view=article\&id=1647 8\& Itemid=1107>. Acesso em: 24/10/2012.

UFPR. Comitê Assessor de Extensão. Pró-Reitoria de Extensão e Cultura. Atas de Reuniões: 1981-2010. Curitiba - PR.

. Conselho de Administração. Resolução oo 158 de 1984. Cria a Coordenação de Extensão no âmbito da Universidade Federal do Paraná. Curitiba - PR.

. Conselho de Ensino e Pesquisa. Resolução CEP no 12 de 1973. Regulamenta os Cursos de Extensão na Universidade Federal do Paraná. Curitiba - PR.

Conselho de Ensino e Pesquisa. Resolução CEP no 03 de 1981. Dispõe sobre os Cursos de Extensão na Universidade Federal do Paraná. Curitiba - PR.

. Conselho de Ensino e Pesquisa. Resolução CEP no 08 de 1983. Dispõe sobre os Cursos de Extensão na Universidade Federal do Paraná. Curitiba - PR.

. Conselho de Ensino e Pesquisa. Resolução CEP o 56 de 1988. Dispõe sobre Atividades de Extensão na Universidade Federal do Paraná. Curitiba - PR.

. Conselho de Ensino e Pesquisa. Resolução CEP no 16 de 1991. Fixa Normas para execução do Programa Bolsa Extensão para estudantes de graduação da Universidade Federal do Paraná. Curitiba - PR.

Conselho de Ensino e Pesquisa. Resolução CEP no 24 de 1993. Dispõe sobre as Atividades de Extensão na Universidade Federal do Paraná. Curitiba - PR.

. Conselho de Ensino e Pesquisa e Extensão. Resolução CEPE o 23 de 2001. Dispõe sobre Atividades de Extensão na Universidade Federal do Paraná. Curitiba - PR.

. Conselho de Ensino e Pesquisa e Extensão. Resolução CEPE no 70 de 2008. Dispõe sobre as Ações de Extensão na Universidade Federal do Paraná. Curitiba - PR.

. Conselho de Ensino e Pesquisa e Extensão. Resolução CEPE no 72 de 2011. Dispõe sobre as Atividades de Extensão na Universidade Federal do Paraná. Curitiba - PR.

Conselho Universitário. Resolução COUN oo 06 de 1997. Aprova alterações no Estatuto da Universidade Federal do Paraná. Curitiba - PR.

- Regimento do Centro Universitário de Treinamento e Ação Comunitária do Paraná - CRUTAC-PR, 1973. Curitiba - PR. 
Disponível

Plano de Desenvolvimento Institucional (2012-2016). Curitiba - PR. <http://www.proplan.ufpr.br/portal/arquivos/PDI\%20UFPR\%202012-2016.pdf>. Acesso em: 24/10/2012. jan/jun 2014, p.3-49. ISSN 2358-7180. 
Extensão na Universidade Federal do Paraná: trajetória histórica

Apêndice - Linha do tempo: Extensão (Brasil/UFPR)

Estatuto das Universidades Brasileiras Decreto 19.851/3

Reforma Francisco Campos

Extensão: cursos,

conferências, difusão de

conhecimentos
LDB Lei 4024/61

Menciona Cursos de

Extensão, no mesmo

nível de enunciado dos cursos de especialização

e aperfeiçoamento

BRASIL

1912

1913

1914

1950

1952

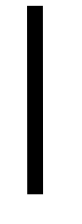

Centro Rural

Universitário de

Treinamento e Ação

Comunitária -

CRUTAC - BR
Decreto - Lei 252/67 Reforma Universitária Art.10 - A Lei 5540/68 Art. 40. Universidade, em sua As instituições de missão educativa, ensino superior: a) por deverá estender à meio de suas comunidade sob atividades de forma de cursos e Extensão,

serviços as proporcionarão aos ativics pesquisa que lhe são coporunidades $\begin{array}{lll}\text { pesquisa que lhe são } & \text { oportunidades de } \\ \text { inerentes } & \text { participação } & \mathrm{em}\end{array}$ $\begin{array}{lll}\text { participação em } & \text { em } \\ \text { programas } & \text { de }\end{array}$

Projeto Rondon melhoria das melhoria das
condições de vida da comunidade e no

do
Estatuto da UP
Aulas clínicas
para
atendimento a
pessoas
carentes

Estatuto e Regimento da UP Departamento

\section{Cultural/.}

Extensão:

Intercâmbios e Cursos Livres

\section{Federalização $\quad$ Estatuto $\quad$ Estatuto da UFPR}

$$
\text { da UP }
$$

UFPR

de

Extensão

Assistência

pobreza

statuto da UFPR

Art. 28 - Parágrafo 3: Os

cursos de extensão

destinar-se-ão a difundir conhecimentos, técnicas e terão duas modalidades: extensão popular
Cursos de Verão e
início da
Universidade
Volante atualização cultural.
Art. 3o - A formação

universitária objetivará principalmente,

realidades brasileiras dos problemas

regionais, como

também se destinará

aos superiores

interesses

humanidade.

da

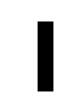

1968

1970

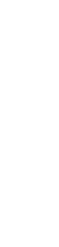

Estatuto da UFPR

Art. $2^{\circ}$ - Alínea "c" - A Universidade, adotando métodos de funcionamento que preservem a unidade de suas funções de ensino e pesquisa, e assegurem a plena utilização de seus recursos humanos e materiais, destina-se: a) contribui para a solução dos problemas de interesse da comunidade, sob a forma de cursos, estudos $\mathrm{e}$ serviços.

[...]

Art. 70: A Universidade proporcionará aos seus alunos: a) por meio de atividades de extensão oportunidade de participação em programas de melhoria das condições de vida da comunidade condiços de vida da comunidade desenvolvimento, b) a realização de programas culturais, artisticos e desportivos; c) a físersidade proporcionara também a Educação física a Educação Moral e Civica que se fará através de meios que propiciem aos seus alunos o conhecimento de seus deveres para com a sociedade e a pátria.

GAIOFATTO, Nadia G; VIEIRA, Carina S. e ANTUNES, Patrícia S. Extensão na Universidade Federal do Paraná: trajetória histórica. Extensão em Foco, Curitiba: Editora da UFPR, nr.9, jan/jun 2014, p.3-49. ISSN 2358-7180. 


BRASIL 1972
UFPR
Mini-Campus
PR - (Coronel
Vívida e Foz
do Iguaçu)
CRUTAC / PR
Projeto Rondon
Campus
Avançado de
Imperatriz -MA
(1972-1985)

Resolução CEP 12/73

Art. 10 Entendem-se como cursos de Extensão, todos aqueles programados a serviço da comunidade ou a que se destinarem a complementar o ensino e a pesquisa.

Art. 56 - Os serviços de Extensão sob forma de serviços especiais, inclusive assessoria atenderão a consultas e compreenderão estudos, a elaboração de projetos concernentes à matéria científica, técnica e educacional, bem como a participacão em qualquer outra iniciativa de domínio científico, tecnológico, intelectual artístico.
Regimento da UFPR Criação da PRAC - PróReitoria de Assuntos Comunitários

Art 55 - Por meio de atividades de extensão a Universidade contribuirá para o desenvolvimento material e espiritual da comunidade.

Estatuto da UFPR - Art. 31, a) os serviços de Assuntos Comunitarios visaráo promover Extensão das atividades de ensino e pesquisa com o objetivo de contribuir para o progresso material da comunidade; b) relacionar a Universidade com a comunidade [...] c) pesquisar e estudar os problemas paranaenses ...l para suas soluções; [...].
Coordenadoria de

1974
Plano de Trabalho de Extensão Universitária (MEC) universidade e a sociedade.

Constituição Federal Art. 207 As Universidades gozam de autonomia didático-científica, administrativa e de gestão financeira e patrimonial e obedecerão ao princípio de indissociabilidade entre ensino, pesquisa e extensão.

1984

1985
Criação da

Divisão de

Extensão e

Cultura (MEC)

1990

Portaria 66/93 SESu/MEC Cria a Comissão de Extensão Universitária (MEC)

Criação do Programa de Fomento Extensão
Resolução 56/88 do CEP Art. $2^{\circ}$ - São considerados universitária, trabalhos envolvendo

departamentos e demais órgãos da UFPR estudantes e professores, estudantes e professores, em atividades vinculadas a questôes basicas da sociedade brasileira em desenvolvimento com comunidade.

Art. 3ํ- São considerados cursos de Extensão universitária aqueles que, ofertados à comunidade objetivando a divulgação do conhecimento, de integracão Universidade e Sociedade. [...] Dispõe sobre as ações de Extensão na UFPR programas de Extensão dinamização do processo

$\begin{array}{cc} & \\ \text { Resolução } & \text { Resolução } \\ 21 / 90 \text { COUN } & 16 / 91 \text { CEP - } \\ \text { - criação da } & \text { institui e } \\ \text { Pró-Reitoria } & \text { regulamenta o } \\ \text { de } & \text { Programa } \\ \text { Extensão e } & \text { Bolsa } \\ \text { Cultura } & \text { Extensão } \\ \text { PROEC } & \end{array}$

Resolução 24/93 - CEP Art. 1ํ - Entende-se a Extensão Universitária como um processo educativo, cultural científico que articula o Ensino e a Pesquisa de forma indissociável e que viabiliza a relação que viabiliza a relação transformadora entre a Sociedade. nacional; III - promover o levantamento do mercado de trabalho [...]; IV - orientar alunos na integração de carreiras prioritárias para desenvolvimento regional nacional; $V$ - assessorar científica, educacional ecnicamente instituições e órgãos governamentais ou privados, $[\ldots] ; \mathrm{VI}$ - manter intercâmbio com instituições

GAIOFATTO, Nadia G; VIEIRA, Carina S. e ANTUNES, Patrícia S. Extensão na Universidade Federal do Paraná: trajetória histórica. Extensão em Foco, Curitiba: Editora da UFPR, nr.9, jan/jun 2014, p.3-49. ISSN 2358-7180. 
LDB - Lei no 9394/96 - Art. 43‥ A educação superior tem por finalidade: I- estimular a criação cultural e 0 desenvolvimento do espírito científico e do
pensamento reflexivo; II- formar diplomados nas pensamento reflexivo; II- formar diplomados nas participação no desenvolvimento da sociedade brasileira, e colaborar na sua formação contínua; IIIincentivar o trabalho de pesquisa e investigação científica [...] ; IV- promover a divulgação de conhecimentos culturais, científicos e técnicos [...]; Vsuscitar o desejo permanente de aperfeiçoamento cultural e profissional [...]; VI- estimular o conhecimento dos problemas do mundo presente [...] prestar serviços especializados à comunidade e estabelecer com esta uma relação de reciprocidade; VII - promover a Extensão, aberta à participação da população, visando à difusão das conquistas e benefícios resultantes da criação cultural e da pesquisa científica e tecnológica geradas na instituição.
Constituição do Plano Nacional de Extensão Universitária - Objetivos: reafirmar a Extensão universitária como processo acadêmico definido efetivado em função das exigências da realidade indispensável na formação do aluno, na qualificação formaça do aluno, na qualificação do professor e no intercâmbio com a sociedade; assegurar a relação sociedade [...]; dar prioridade às práticas voltadas para o atendimento de necessidades sociais emergentes [...] renda; e estimular atividades cujo desenvolvimento implique relações multi, inter e/ou transdisciplinares

interprofissionais de setores da universidade e da sociedade.
Lei $\mathrm{n}$ - 10.172/01 - Plano Nacional de Educação (PNE): Meta 23 do item 4 mplantar o Programa de Desenvolvimento Extensão Universitária em todas as Instituicõos Federais de Ensino Superior no quadrienio 2001-2004 assegurar que, no mínimo, $10 \%$ de créditos exigidos para a graduação no ensino superior no País será reservado para a atuação dos alunos em ações extensionistas.
Plano Nacional de Extensão Universitária FORPROEX: define as Diretrizes para a Extensão Universitária que devem estar presentes em todas as ações de Extensão expressas em quatro expressas em quatro eixos: Impacto transformação: nteração dialógica; Interdisciplinaridade; ndissociabilidad entre ensino, pesquisa e extensão
Proposta de lei Plano Naciona de Educação 2011-2020 Meta 12: elevar a taxa 12. elevar a taxa bruta de matrícula educação supsegurando qualidade da qualidade ferta. Estratégias: $[\ldots]$ 12.7. Assegurar no mínimo, $10 \%$ do total de créditos curriculares exigidos para programas em projetos de projoctos Extensão niversitária

2001

2002

2007

2008

2011 graduação em

FORPROEXT Política Nacional de Extensão Universitária. Alguns objetivos: reafirmar a Extensão Universitária como processo acadêmico definido e efetivado em função das exigências da realidade, além de indispensável na formação do estudante, na qualificação do professor $e$ no intercâmbio com a sociedade; conquistar o reconhecimento, por parte do Poder Público e da sociedade brasileira, da Extensão Universitária como dimensão relevante da atuação universitária, integrada a uma nova concepção de Universidade Pública e de seu projeto político-institucional. Nova Diretriz para a Extensão Universitária: Impacto na Formação do Estudante.

Extensão explicitada no Currículo Lattes (CNPq)

I
2012
UFPR

Resolução №06/97 do COUN aprova as alterações no Estatuto: alteração de denominação de CEP para CEPE:

Art. 15 - A Administração Superior da Universidade será exercida pelos Conselhos de Planejamento Adming Planejamento e Administração (COPLAD), de Ensino Pesquisa e Extensão (CEPE) e Universitário (COUN) como órgãos normativos, deliberativos e consultivos, pela Reitoria como órgão executivo central.
Resolução no 23/01 do CEPE - dispõe sobre as ações de Extensão na UFPR

Art.10 - A Extensão Universitária é o processo educativo, cultural e científico que, articulado de orma indissociável ao Ensino e à Pesquisa, viabiliz a relação transformadora entre a Universidade e a Sociedade

Art. 20 - As atividades de Extensão serão coordenadas pela Pró-Reitoria de Extensão e Cultura (PROEC) quem, de acordo com o Regimento Geral da Universidade, cabe propor aos Conselhos Superiores univa universitána, bem como fonentar, acompanhar, avalia articular e divulgar as atividades de Extensão no ambito interno e externo da Universidade, contando com um Comite Assessor de Extensão (CAEX) e Comitês Setoriais. normas e políticas sobre atividades de Extensão

\section{I}

$1^{\circ}$ Encontro de Extensão e Cultura (ENEC)

Ata 149 - CAEX: O Plano estratégico da gestão atual da PROEC é priorizar o caráter interdisciplina da Extensão universitária trazendo-a para um níve de reconhecimento igual ao dado à pesquisa e ao ensino.

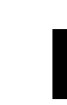

Resolução CEPE 70/08 - dispõe sobre as ações de Extensão n UFPR -

em consonância com as diretrizes do FORPROEX esolução 25/11 CEPE Programa Bolsa Extensão

Resolução 72/11 CEPE Dispõe sobre as Atividades de Extensão na UFPR. Reformulação em Reformulação em consonatria com as diretrizes do FORPROEX e do 7416/2010 (Bolsas)
GAIOFATTO, Nadia G; VIEIRA, Carina S. e ANTUNES, Patrícia S. Extensão na Universidade Federal do Paraná: trajetória histórica. Extensão em Foco, Curitiba: Editora da UFPR, nr.9, jan/jun 2014, p.3-49. ISSN 2358-7180. 